\title{
Review of porphyrin-based photodynamic therapy materials
}

\author{
Jia Tian ${ }^{\mathrm{a}}$, Baoxuan Huang a, Mian Hasnain Nawaz ${ }^{\mathrm{b}}$, Weian Zhang ${ }^{\mathrm{a}, \Uparrow}$ \\ a Shanghai Key Laboratory of Functional Materials Chemistry, School of Chemistry and Molecular Engineering, East China University of Science and Technology, Meilong Road \\ 130, Shanghai 200237, PR China \\ ${ }^{\mathrm{b}}$ Interdisciplinary Research Centre in Biomdical Materials, COMSATS University Islamabad, Lahore Campus, Lahore 54000, Pakistan
}

\section{Abstract}

Photodynamic therapy (PDT) has emerged as a promising and non-invasive modality for cancer treatments. Photosensitizers, as one of the essential elements in PDT, play a crucial role in the practical applications of PDT. Exposure to suitable light irradiation leads these photosensitizers to absorb the energy and move to excited state. Eventually, they transfer the energy to surrounding molecules and produce reactive oxygen species (ROS), particularly the singlet oxygen $\left({ }^{1} \mathrm{O}_{2}\right)$. Porphyrins, consisting of tetrapyrrole bridged with four methylene groups, are the classical and typical photosensitizers. However, the poor water-solubility, low biostability and non-specific tumor-targeting properties of porphyrins limit the PDT efficiency and their clinical applications. Thus, in order to promote the PDT efficiency of porphyrins, a variety of modification and functionalization strategies have been developed to

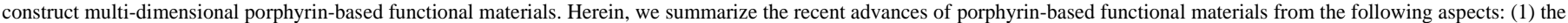

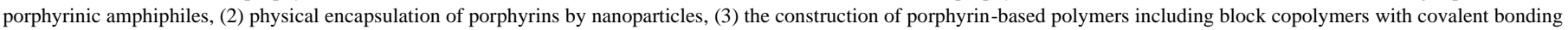
and supramolecular polymers with non-covalent bonding, and (4) porphyrin-based organic frameworks. We believe that the development of porphyrin-based functional materials provide more fascinating superiorities in PDT and dramatically expand the potentials and possibilities in cancer treatments.

\section{Introduction}

\subsection{Porphyrins}

Porphyrins are a class of tetrapyrrole compounds, which consist of a planar porphin core surrounded by substituent groups [1-3]. It is undoubted and well documented that porphyrins are one of invaluable and ubiquitous molecular species, which play critical roles in living systems including photosynthesis [4-7]. The stable macrocyclic arrangement of porphin core forms an ideal anchoring site for metal atoms complexation [8]. In addition, various derivatives can be obtained via introducing different substituents at pyrrolic meso- or b-positions. Although the structure of porphyrins was suggested more than one hundred years ago, the studies of their synthesis, assemblies and applications have always been of great interest in the scientific community [9].

Due to the high absorption coefficient and superior capabilities of energy-, hydrogen- and electron-transfer, porphyrins present diverse outstanding photophysical and photochemical properties. These intrinsic superior properties of porphyrin render their extravagant studies in solar cells, [10-12] catalysis, [13] imaging, [14] molecular electronics [15] and biomedicines [16]. Considering the several reviews, summarizing the synthesis, self-assembly, and applications of porphyrins in solar cells, catalysis, imaging and drug delivery, the aim of this review is to specifically focus the porphyrin-based materials for photodynamic therapy in the last five years.

\subsection{Photodynamic therapy}

Photodynamic therapy (PDT) refers to the administration of photosensitizers, light and oxygen molecules to generate cytotoxic reactive oxygen species (ROS), particularly singlet oxygen $\left({ }^{1} \mathrm{O}_{2}\right)[17,18]$. PDT is a site-specific and non-invasive treatment, and has arisen intensive interest in chemistry, materials and biology $[19,20]$. Among the three elements (photosensitizers, light and oxygen molecules), photosensitizers are the essential parameter in PDT, which directly affect the PDT efficiency $[21,22]$.

As presented in Fig. 1, the modified Jablonski diagram illustrates the main photochemical reactions occurring in PDT process [17]. Upon the light irradiation of suitable wavelength, photosensitizers can be transformed from the ground state $\left(\mathrm{S}_{0}\right)$ to excited singlet state $\left(\mathrm{S}_{1}\right)$. These excited photosensitizers can then either relax back to $S_{0}$ state accompanying with a fluorescence photon emission or can be transformed to excited triplet state $\left(\mathrm{T}_{1}\right)$ by intersystem crossing. Furthermore, the energy of photosensitizers in $\mathrm{T}_{1}$ state can either be relaxed by a phosphorescent photon exhibiting phosphorescence or can be transferred to ambient molecules by photochemical reaction by type-I and type-II paths. In type-I path, photosensitizers in $\mathrm{T}_{1}$ state undergo an electron- or hydrogentransfer process to produce free radicals, which further interact with water or oxygen molecules leading to the production of

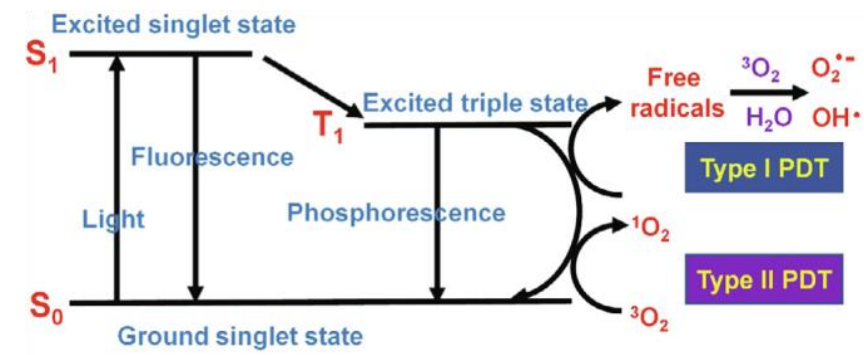

hydroxyl radicals $(\mathrm{OH})$ or superoxide anions $\left(\mathrm{O}_{2}^{-}\right)$[23]. It is worth noting that the type-I PDT can undergo in hypoxic condition, particularly in hypoxic tumor microenvironment of deep-seated tumors. On the other hands, in well-oxygenated condition, photosensitizers in $\mathrm{T}_{1}$ state participate an energy-transfer process with localized ${ }^{3} \mathrm{O}_{2}$ resulting in the formation of highly cytotoxic singlet oxygen $\left({ }^{1} \mathrm{O}_{2}\right)$, [24] which is known as type-II PDT. It has been reported that type-II path generally dominates PDT process. However, the high concentration of photosensitizers and hypoxic condition can lead the type-I PDT pathway dominantly. PDT as a whole has been recognized as a promising anticancer strategy with the merits of non-invasiveness and spatiotemporal control [25-27].

Besides photosensitizers, the light source is another critical parameter for the PDT process. Since living tissues can largely reflect and decay the light, the limited tissue penetration depth and delivery efficiency of light are the essential barriers in PDT especially for deep tumor treatments. The light penetration depth in tissues during PDT is affected by several factors including wavelength and intensity of light as well as tissue physiology. There is strong absorption in the visible spectrum 
below $650 \mathrm{~nm}$ by the endogenous fluorophores. In addition, near-infrared (NIR) light with wavelength longer than $900 \mathrm{~nm}$ is probably not strong enough to activate the photosensitizers [28]. Thus, the light source generally used in a PDT process ranges from 650 to $850 \mathrm{~nm}$.

$[17,20,29]$ Furthermore, the optimization of specific light intensity to get effective therapeutic efficacy and reduce photodamage to normal tissues dragged much effort [30].

Singlet oxygen generation efficiency is another crucial criterion to evaluate PDT efficiency [22,31]. Several dyes have been used as photo probes for detecting the generation of singlet oxygen. For example, the absorbance of 1,3-diphenylisobenzofuran (DPBF) is monitored as the function of light irradiation dosage to indicate the extracellular generation of ${ }^{1} \mathrm{O}_{2}$ for photosensitizers. The reaction between DPBF and ${ }^{1} \mathrm{O}_{2}$ can induce an absorbance loss of DPBF [32,33]. Similarly the fluorescence enhancement of singlet oxygen sensor green ( $\mathrm{SOSG}$ ) can be employed to quantify singlet oxygen generation $[34,35]$. The intracellular ${ }^{1} \mathrm{O}_{2}$ generation can also be estimated by using 2,7-dichlorofluorescein diacetate (DCFH-DA) as an indicator because DCFH-DA can be oxidized by ${ }^{1} \mathrm{O}_{2}$ to dichlorofluorescein (DCF) yielding green fluorescence [36,37].

\section{Porphyrin and its derivatives in PDT}

Porphyrin and its derivatives including chlorins and bacteriochlorins are one of the most typical and useful photosensitizers in PDT [38,39]. The longest absorption of porphyrins is in red light portion, allowing the light penetration to deep tissues which helps in deep tumor treatments. The chemical structures of porphyrins and their derivatives commonly used in PDT are presented in Fig. 2. So far, the most universal studied and used photosensitizer is Photofrin, which is isolated from the hematoporphyrin mixtures [40]. However, owing to the accumulation in the skin, the compli-

Fig. 1. Modified Jablonski diagram showing the formation of reactive oxygen radicals in type-I and type-II PDT

cation of severe skin photosensitizations generally accompanies the treatment of Photofrin. In addition, the limited watersolubility, low circulation half-life and low tumor-specificity of traditional porphyrins lead to their limited PDT efficiency. Therefore, a variety of chemical functionalization and physical encapsulation strategies have applied to overcome the shortcomings and enhance the PDT efficiency of porphyrins [41,42].

\subsection{Porphyrinic amphiphiles}

On the basis of chemical coupling reactions and self-assembly, hydrophilic or amphiphilic molecules including peptides, saccharide, lipids and surfactants can be coupled with porphyrins. These

Fig. 2. Structures of porphyrins and their derivatives commonly used in photodynamic therapy.

adopted strategies as well as introduced functionalities produce functionalized porphyrinic amphiphiles with improved watersolubility and retained intrinsic properties of porphyrin [43-45]. Additionally, the amphiphilic porphyrinic photosensitizers can further self-assemble into nano-sized particles to passively accumulate at tumor sites via enhanced permeability and retention (EPR) effect.

To introduce good biocompatibility, biodegradability and nonimmunogenicity in the functionalized porphyrins, peptides being the basic units for proteins are the ideal candidates [46,47]. A variety of substructures and functionalities can be obtained from the amount and different sequences of amino acid in peptides. Thus, peptides in general have been recognized as a promising candidate for biomedical application [48,49]. For example, it has been reported that porphyrinated nanofibers were constructed on tumor site from the peptide-porphyrin conjugates. It was achieved by conjugating tumor-targeting ligand and a responsive linker by the standard solid-phase peptide synthesis techniques (Fig. 3) [50]. The nanofibers presented aggregation-induced retention effect, leading to significant improvement in photoacoustic (PA) imaging signals and PDT efficacy. In addition, the peptideporphyrin conjugates also self-assembled to "sandwich" dimeric structure by the consociation between chlorins and $\mathrm{Cu}^{2+}[48]$. Similarly, the peptide-chlorophyll-based dimer with terminal mannose units triggered the targeting property to macrophage and eliminated intracellular bacterial infections by PDT. 

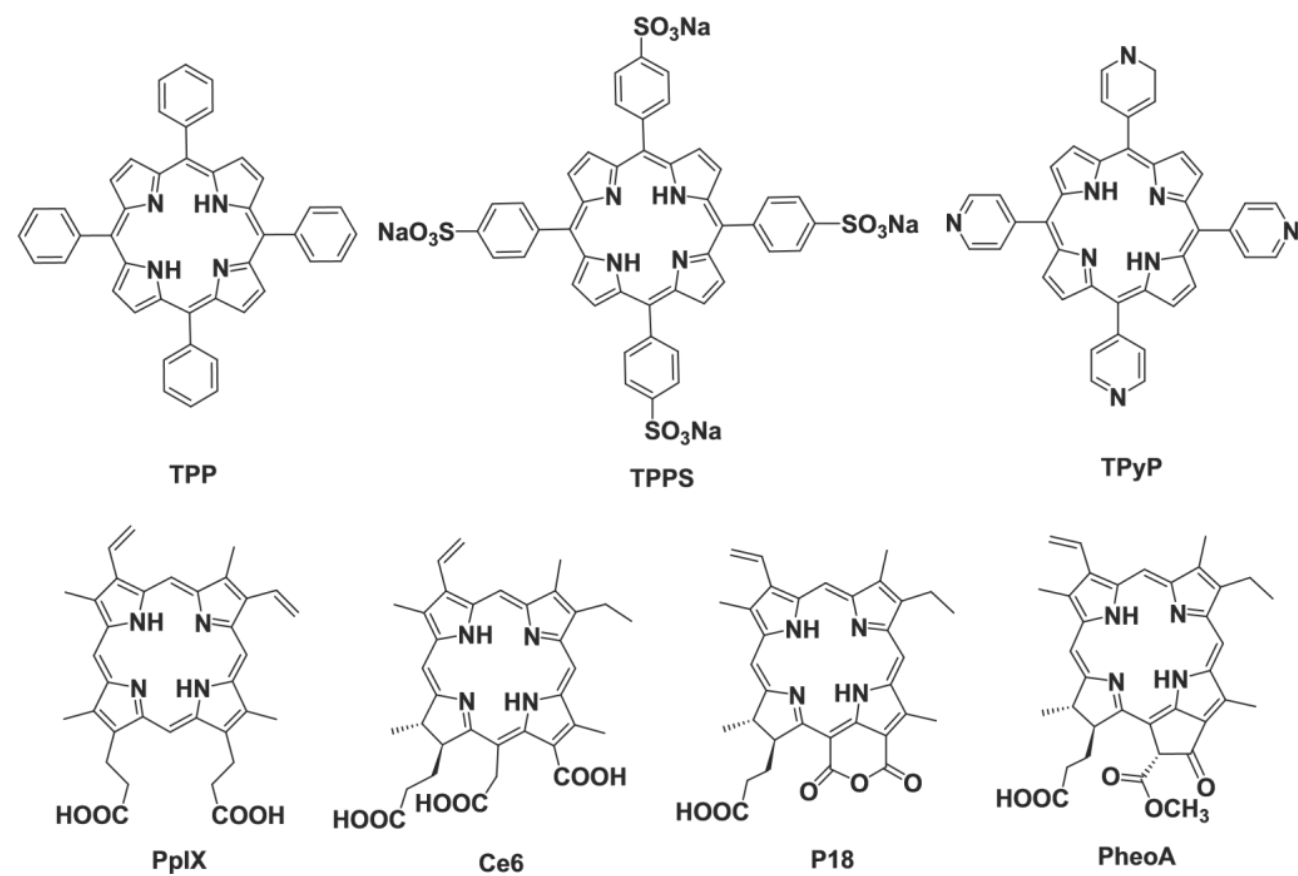

Recently, Yan and coworkers pioneered several research works on the peptide-tuned porphyrin-based self-assemblies for anticancer photodynamic and

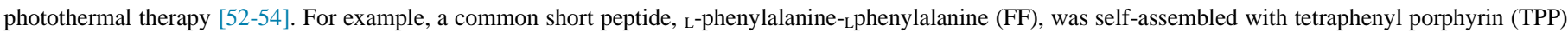
and zinc ions to construct spherical nanoparticles by multicomponent coordination self-assembly strategy (Fig. 4) [51]. These well-defined metalloporphyrin nanodrugs exhibited high loading rate of porphyrins, sensitive redox- and $\mathrm{pH}$-dualresponsiveness which eventually enhanced its PDT efficacy. In addition, photothermal nanodots were synthesized in an effort to couple tetraphenyl porphyrin with FF to obtain peptideporphyrin conjug ates (TPP-G-FF) [55]. The conjugates selfassembled into well-defined uniform nanodots with controllable sizes ranging from 20 to $100 \mathrm{~nm}$. Porphyrins arranged to regular J-aggregation substructures in nanodots, leading to the high local heating production along with high generation of singlet oxygen and fluorescence emission.

Similarly, liposomes, closed bilayer lipid systems, have emerged as interesting nanocarriers for varieties of drugs to provide better therapeutic efficacy against drug-resistant tumors with lower cardiotoxicity [56,57]. Several research groups have reported the construction and biomedical applications of porphyrin-liposomes by the functionalization of porphyrins with lipids via esterification or amidation reactions. It is a well established fact that porphyrins generally conjugate with amphiphilic lipids with a high loading content [58-61]. Because of the amphiphilicity of porphyrin lipids, they could directly self-assemble into porphyrin liposomes in physiological condition with the porphyrin motifs at the walls. Such smart self-arrangement induced the fascinating merits of porphyrin-liposomes adducts including the remarkable bioimaging, [14] photodynamic [62] and photothermal effects [58]. To support this hypothesis, TPP was grafted onto the lipid at the junction point to obtain lipid-porphyrin conjugates which further encapsulated the DOX and cholesterol. This encapsulation resulted into self-assembled nanoparticles which could well perform the fluorescence imaging-guided synergistic chemo-photodynamic therapy (Fig. 5) [63].

Thus, the fuctionalization of porphyrins with hydrophilic or amphiphilic molecules by chemical modification and coupling reactions can significantly improve the water-solubility and biocompatibility of porphyrins. More importantly, they can selfassemble into porphyrin-based micelles, liposomes, nanodots with high porphyrin loading content. The dense packing of porphyrin motif results in the promising photophysical and chemical properties, which is beneficial to the PDT application.

\subsection{Porphyrin-loaded nanoparticles}

Despite of the chemical functionalization of porphyrins, physical encapsulation is recognized as another commonly used strategy to enhance the water-solubility and biocompatibility of por- 

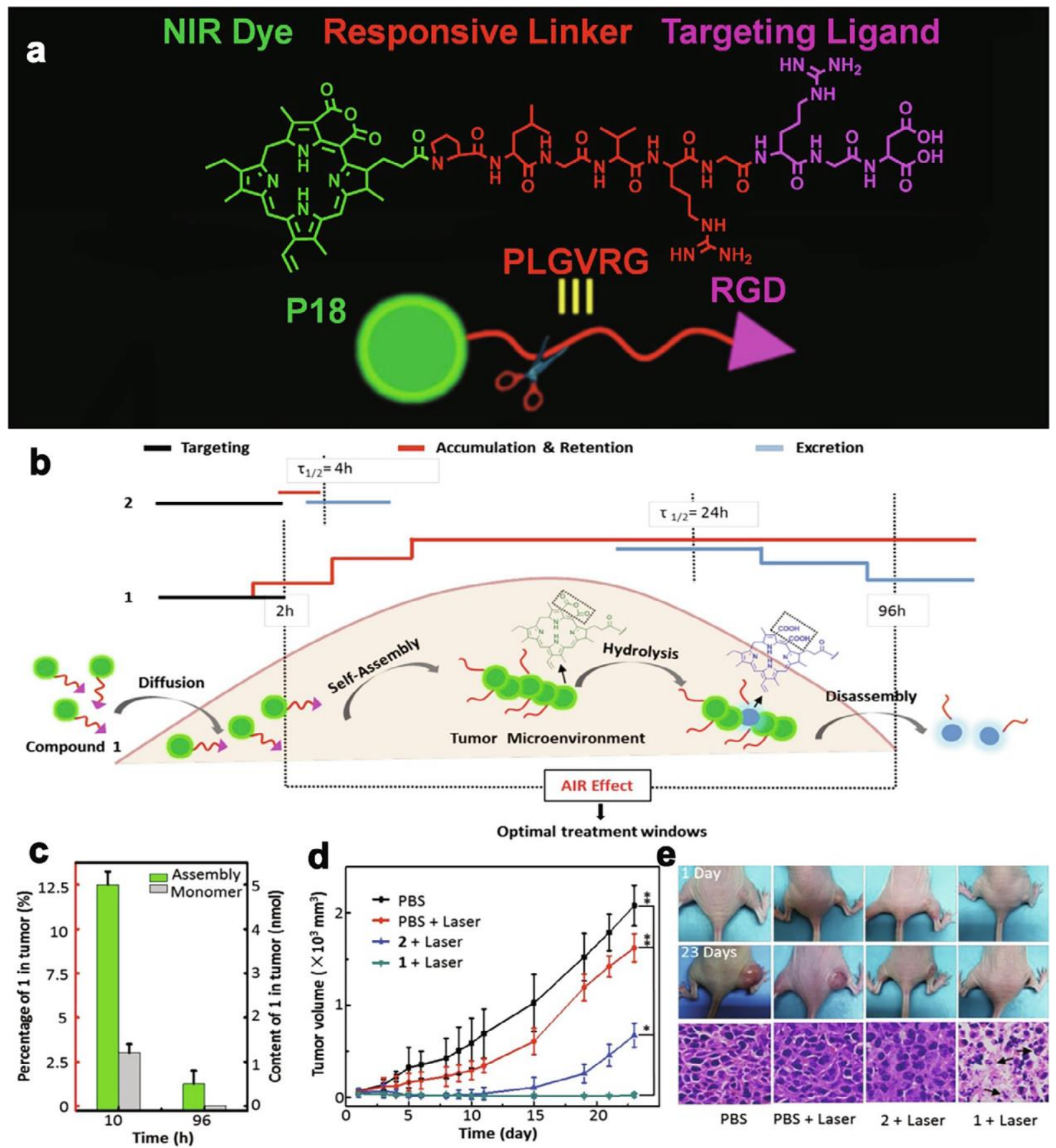

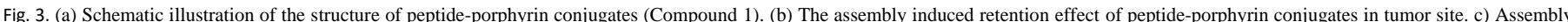

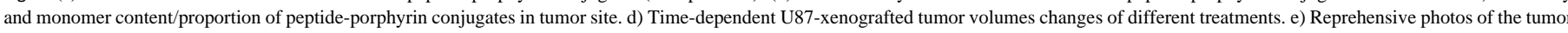

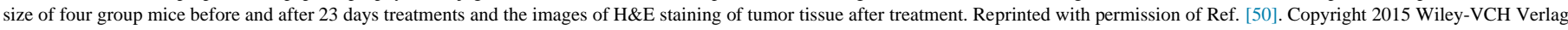
$\mathrm{GmbH} \& \mathrm{Co}$. KGaA, Weinheim.

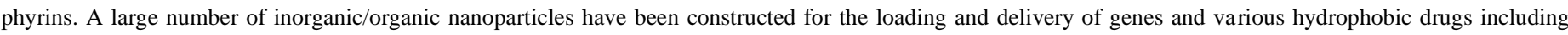

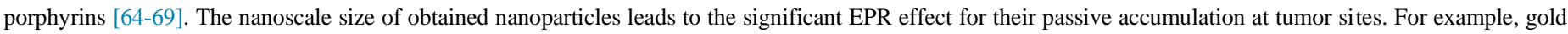

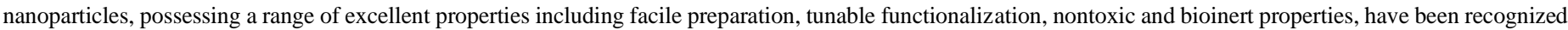
as an attractive nanocarrier for PDT applications [70,71].

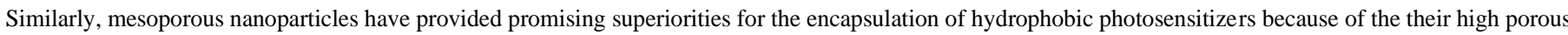
volume and large surface area [72]. Mesopores supply a protected physiological environment, passive tumor-targeting, and sustained photosensitizer release [73,74]. Shi et al. reported a variety of research works focusing on the biomedical applications of mesoporous silica nanoparticles. For example, porphyrin-loaded core-shell functional nanoparticles were constructed by a gadolinium-doped upconversion nanoparticle (UCNP) core and mesoporous silica shell (Fig. 6) [75]. Porphyrins chelated with manganese $(\mathrm{Mn})$ ions were then grafted onto the mesoporosity of these core-shell nanoparticles by an amidation reaction, which showed high magnetic resonance imaging 
a

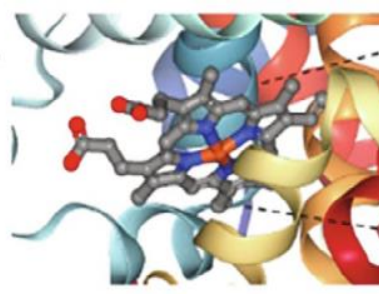

Hemoglobin

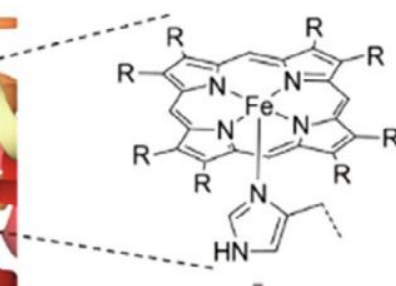

b

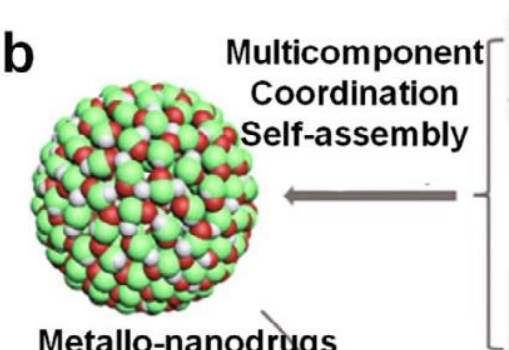

Metallo-nanodrugs

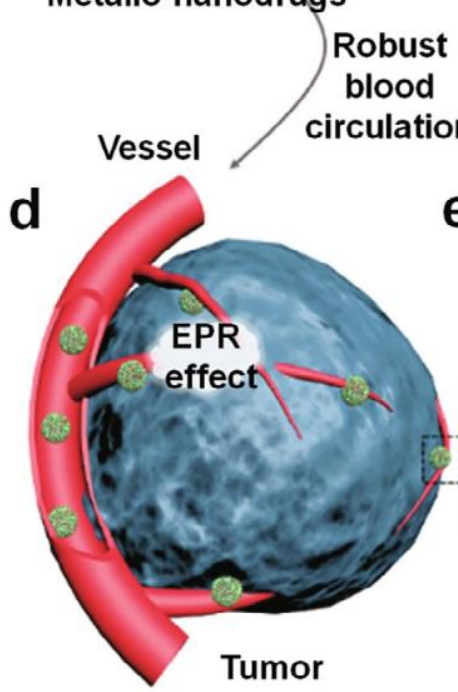

Photosensitizer

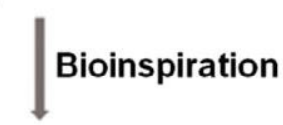

c
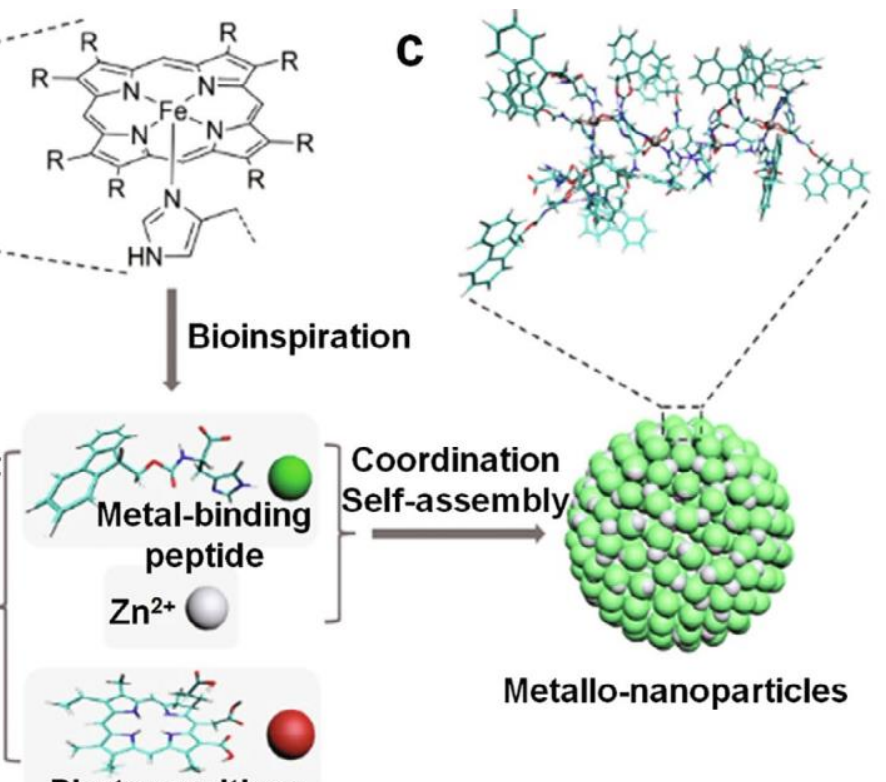

Metallo-nanoparticles

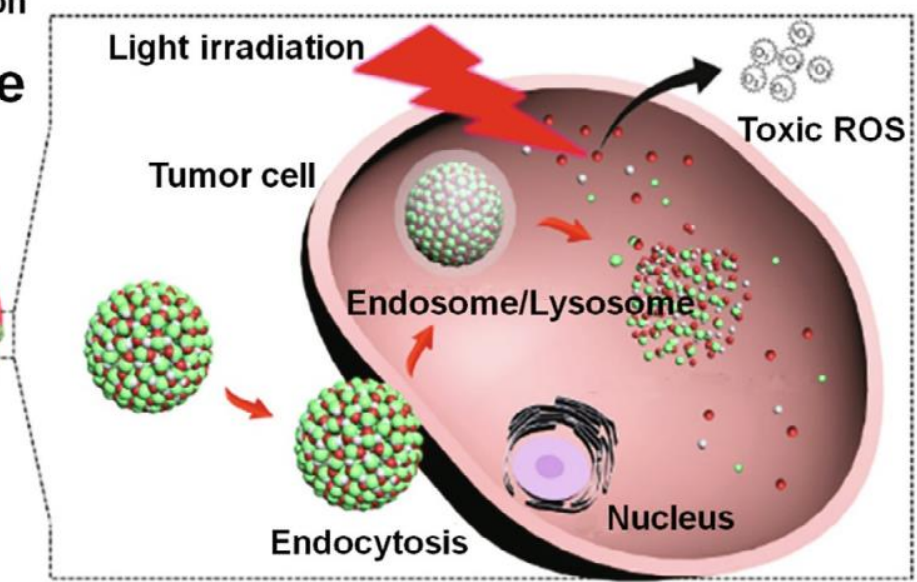

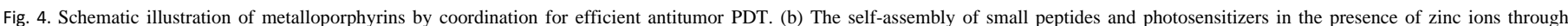

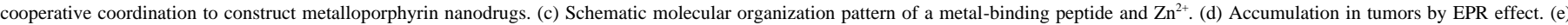
Cellular internalization of metalloporphyrin nanoparticles and efficient PDT. Reprinted with permission of Ref. [51]. Copyright 2018, American Chemical Society.

(MRI) performance and singlet oxygen generation via sonodynamic therapy. Since the low tissue-penetrating depth of light limited the antitumor efficacy of PDT, sonodynamic therapy by ultrasound waves presented superiority to the tumor tissue in deep site, particularly to the hypoxic tumor tissue.

However, the recent studies showed that the inorganic nanoparticles used in nanomedicine possess important issue of metabolization [76]. The toxicity and unwanted stability of the nanoparticles bear deep concerns in translating the scientific innovation into clinical applications [77,78]. Several studies have been explored that various physicochemical properties including the particle size, chemical composition, surface charge, surface modification, and surface roughness of nanoparticles play crucial roles in their toxicity and long term stability [79,80]. Thus, some cleavable units including disulfide [81] and iron [82], which can be broken under the distinctive tumor microenvironment, were introduced into inorganic nanoparticles to acquire stimulireponsive biodegradability.

Besides, based on the good dispersity and self-assembly of surfactants, Fan and co-workers constructed porphyrin-based nanodisks, nanowires, [83] nanocubes, [84] and nanorods [85] using the noncovalent interaction between ZnTPP and surfactants. These constructs promoted energy transfer between porphyrin molecules, leading to a red shift in absorption for enhanced photocatalytic and PDT performance.

More recently, organic nanocarriers have attracted wide interests because of their facile molecular design, tunable function modification and good biocompatibility. A variety of organic nanoparticles, vesicles, nanocapsules have been fabricated to load porphyrinic photosensitizers [86-89]. For example, our group reported the construction of porphyrin-loaded hollow nanocapsules to control the release of photosensitizers triggered by the over expressed glutathione (GSH) in tumor microenvironment [90]. Although diverse porphyrin-based nanoparticles with various functions have been studied, the possible leakage release of porphyrins and poor reproducibility are the main drawbacks for their potential applications. 


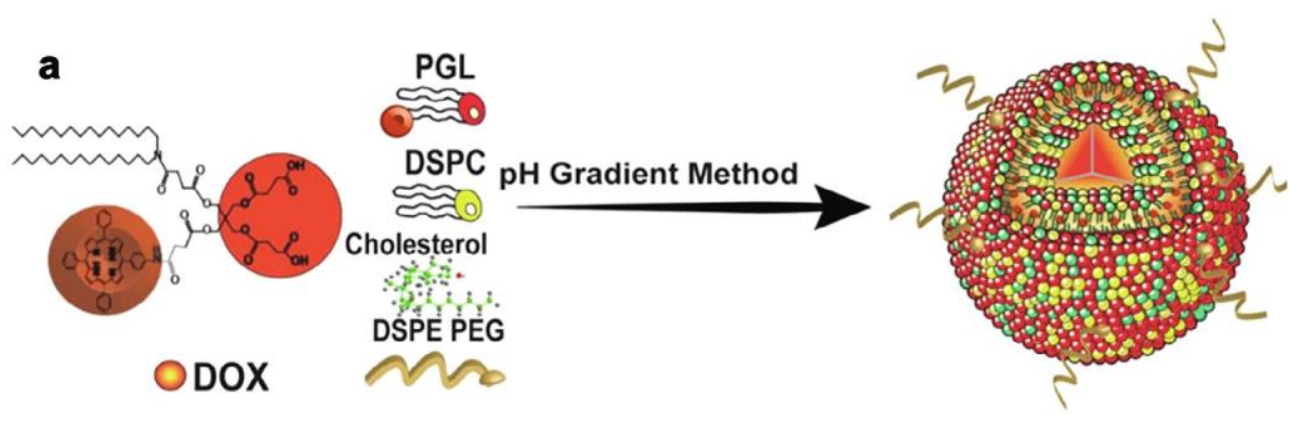

b

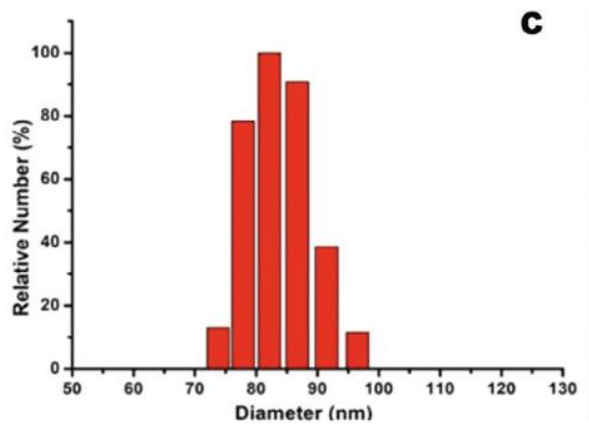

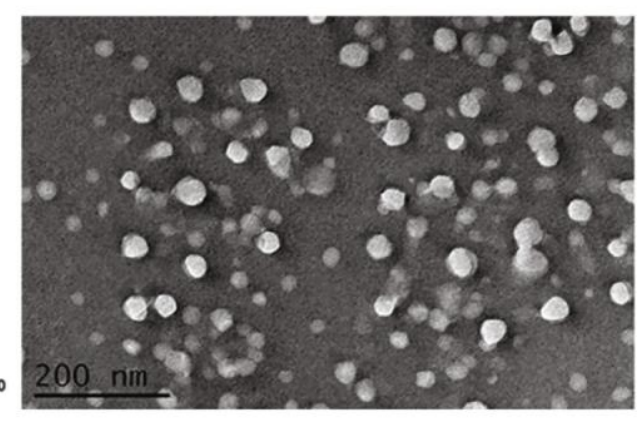

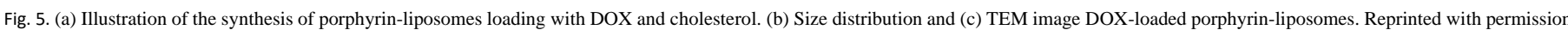
of Ref. [63]. Copyright 2018, Ivyspring international publisher.

3. Porphyrin-based polymers in PDT

During the past decades, porphyrin-based polymers have emerged and presented attractive merits in chemical structure design, self-assembly and biomedical applications. Presence of intrinsic functional groups in porphyrin molecules, induces ease of functionalization rendering variety of customised derivatives to work as the initiator, monomers, chain transfer agents for polymerization, and coupling agents for post polymerization modifications [91,92]. A variety of porphyrin-based block copolymers and supramolecular polymers have been constructed with aim to utilize in biomedicines, particularly, for PDT [93].

\subsection{Porphyrin-based block polymers in PDT}

Due to the development of control/living radical polymerization, the synthesis and self-assembly of block copolymers have attracted extensive interests [94,95]. Among these, the study of photo-responsive functional block copolymers owing to their significant physical and chemical properties is a quite interesting yet challenging research topic [96-99]. As a typical photoresponsive functional unit, porphyrin-based block copolymers have been well studied and used in applications including solar cells, catalysis, light harvesting, and biomedicines [100-103]. Similarly, a good number of studies on porphyrin-based block copolymers have been conducted especially to utilize them in PDT itself and PDT involved therapies [104,105]. According to the previous works, [91,93] there are two major points in the construction of porphyrin-based block copolymers for their usage in PDT: (I) hydrophilic modification is needed for biostability improvement, such as PEGlated coupling and the polymerization of hydrophilic block; (II) Stimuli-responsive functionalization can endow specific adaptability of porphyrin-based block copolymers for the blood circulation and for the particular tumor micro-environment.

In the first strategy, PEG block can be constructed by both coupling of polyethylene glycol (PEG) chains and polymerization of oligo(ethylene-glycol) methyl ether methacrylate. For example, Zhang and co-workers pioneered a research of PEG-block-peptide conjugated with porphyrin units (PPK). This porphyrinic conjugate was self-assembled into uniform nanoparticles and used as mitochondria-targeted self-delivery system with long-term dualstage-light-guided PDT (Fig. 7 )[106]. Consequently, a short irradiation $(5 \mathrm{~min})$ led to the photochemical internalization, while, the long-time irradiation (15 min) resulted in photodynamic therapy. The proapoptosis peptide motif endowed the porphyrin-based nanoparticles with the mitochondria-targeting functionality. After the treatment of light irradiation, the tumor growth was significantly inhibited on the 5th day. The results of tumor weights, tumor images and H\&E staining images confirmed the good in vivo synergistic efficacy of the PPK nanoparticles.

As the second strategy, our group have pioneered systematic research focusing on the synthesis, self-assembly, and biomedical applications of stimuli-responsive porphyrin-based telechelics, [107,108] dendrimers, [109,110] block copolymers, [111-113] and supramolecular polymers [114,115]. However, compared with the possible leakage release of physical encapsulated porphyrin molecules, these could be functionalized as the motifs of polymers by stimuli-responsive covalent bonds in porphyrin-based polymers. For example, TPP units were coupled at the terminal of PEG-b-PCL via a pH-responsive acetal linker to construct porphyrinbased telechelics [107]. More recently, we also used the combination of reversible addition-fragmentation chain transfer (RAFT) polymerization, "click" reactions and coupling reactions to construct the stimuli-responsive porphyrin-based block copolymers. It is obvious that the photophysical and photochemical properties of porphyrins could be significantly improved by the introduction of a hydrophilic block and unique stimuliresponsiveness at tumor sites.

A porphyrin-based block copolymer with upper critical solution temperature (UCST) behavior was synthesized by RAFT polymerization and grafted onto gold nanorods (AuNRs) to construct a polymer/AuNRs hybrid photosensitizer (Fig. 8) [116]. The UCST of hybrid photosensitizers can be modulated around $42 \mathrm{C}$ with the help of feeding ratio of acrylamide (AAm) and acrylonitrile (AN) during reversible addition-fragmentation chain transfer (RAFT) 


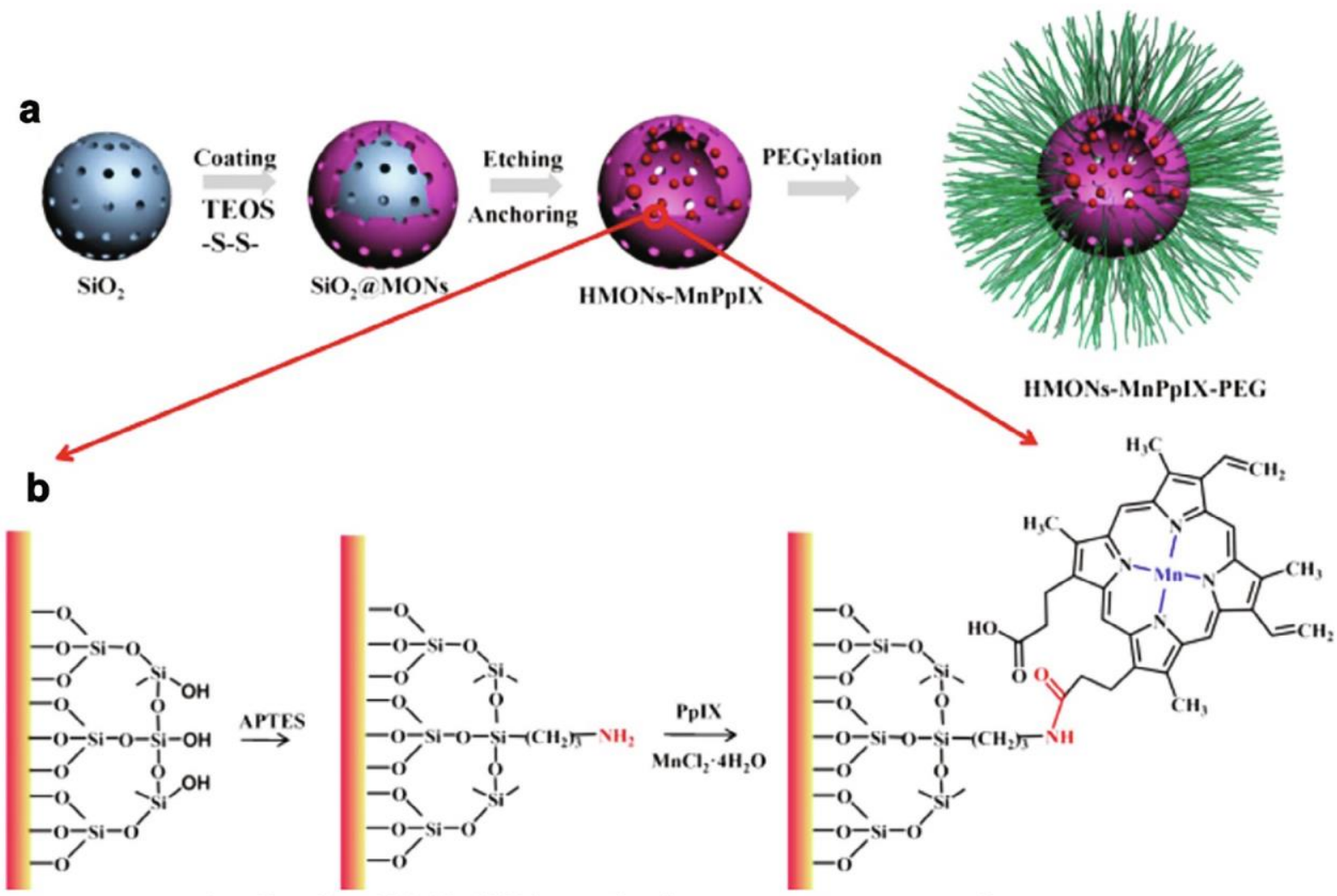

Anchoring MnPpIX into the inner mesopore surface

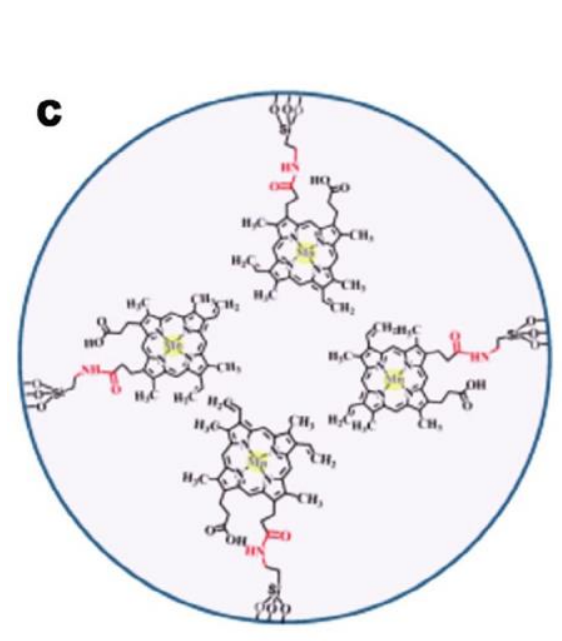

Pore engineering

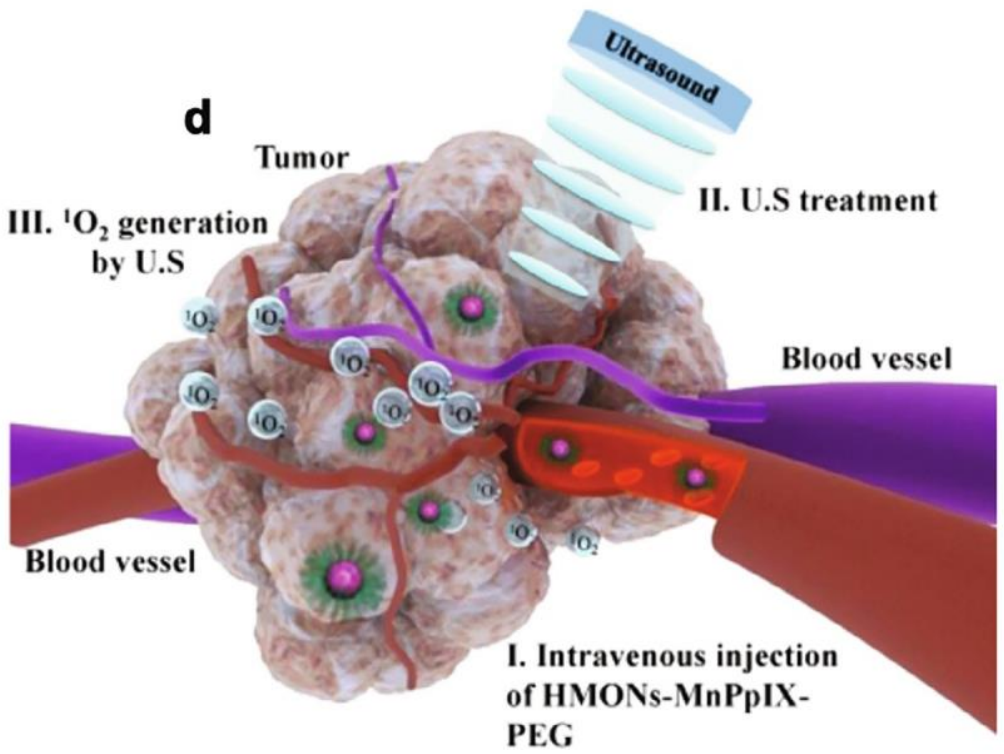

Fig. 6. Illustration of the synthesis, sonodynamic effect and MRI imaging of Mn-porphyrin-modified UCNP-mesoporous silica core-shell nanoparticles. Reprinted with permission of Ref. [75]. Copyright 2017, American Chemical Society.

polymerization. In physiological environment, these porphyrin motifs aggregated together with the collapsed UCST polymers on the surface of AuNRs. In this case the PDT was in "off" state during blood circulation protecting the patients away from sensitive reactions. Upon EPR effect, the hybrid photosensitizers passively accumulated in tumor sites. With the exposure of $808 \mathrm{~nm}$ light irradiation, the local heating produced by AuNRs led to the increasing temperature and eventually resulted in the phase transition of UCST polymers. Simultaneously, the porphyrin motifs were separated by the extended UCST polymer chains and upon the irradiation of $650 \mathrm{~nm}$ light, the PDT of porphyrin motifs were turned "on" in tumor sites and efficiently killed the cancer cells. The research work integrated photothermal and photodynamic therapy, which could provide a path to overcome the sensitive reactions of PDT. 
Recently, our group constructed a unique block copolymer with a polyhedral oligomeric silsesquioxane (POSS)/porphyrin alternating structure for enhanced PDT (Fig. 9) [117]. Porphyrin units modified with styrene derivative and POSS units coupled with maleimide were used as the monomers for RAFT copolymerization. It was noted that the reactivity ratios of styrene and maleic derivatives in polymerization were similar, which led to the copolymer of styrene and maleic derivatives in

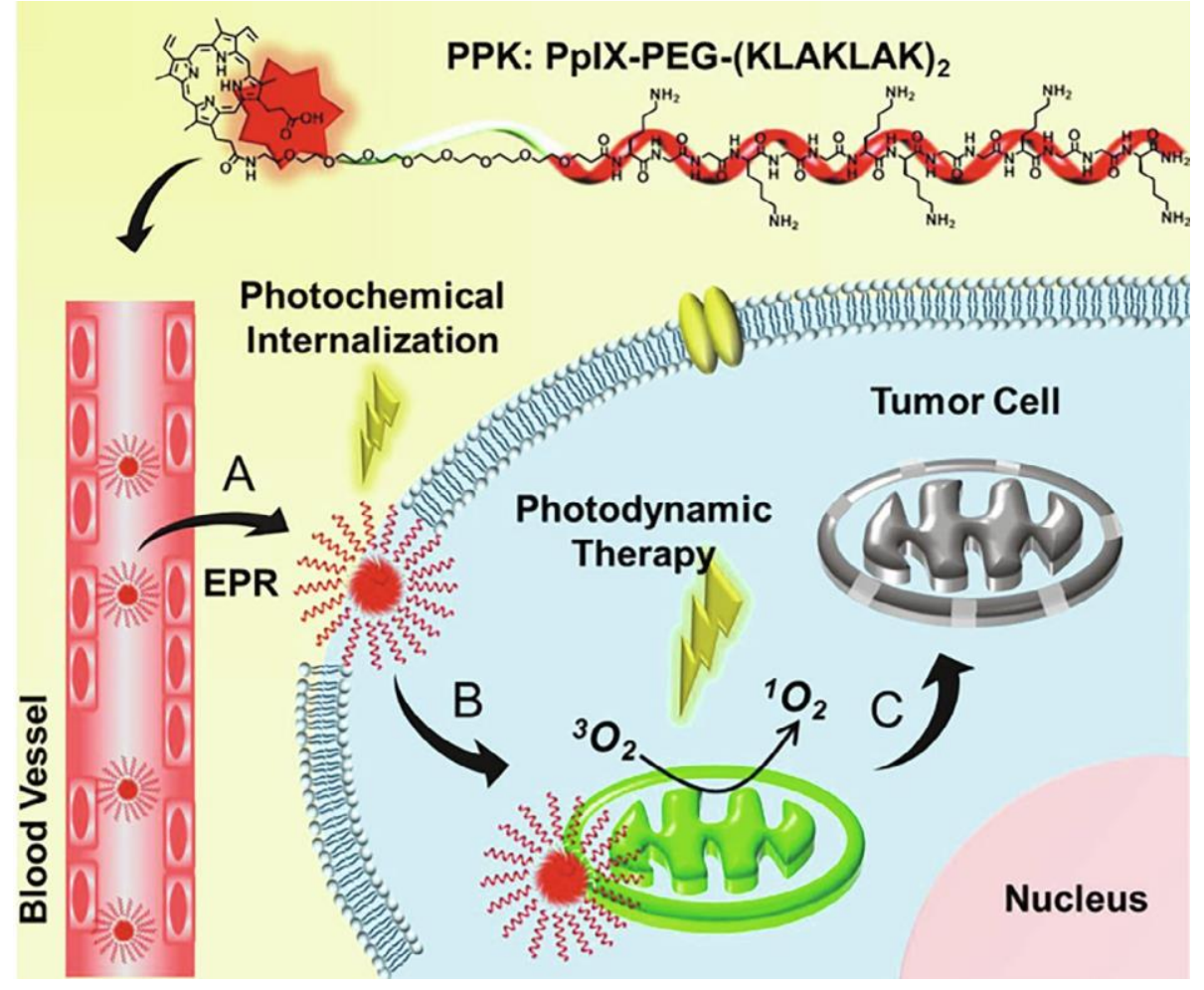

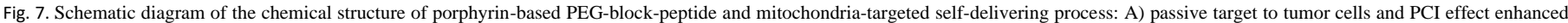

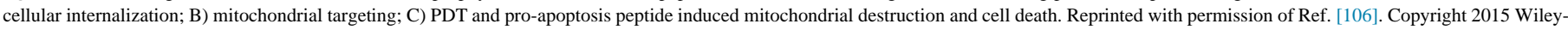
VCH Verlag GmbH \& Co. KGaA, Weinheim.

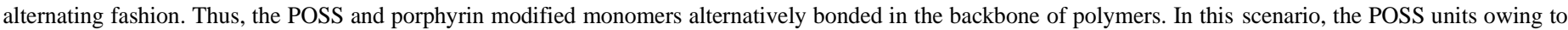

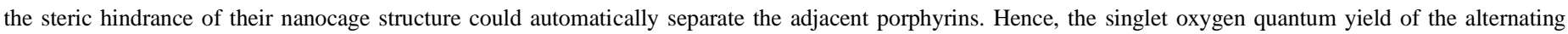

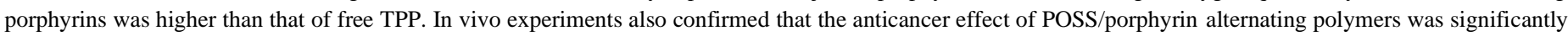
higher than that of porphyrin-based block copolymers without POSS units.

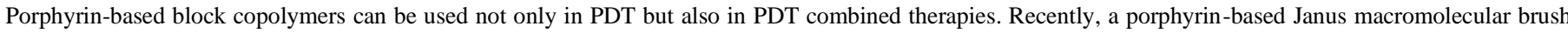

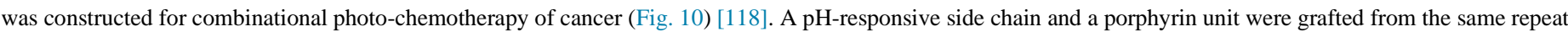

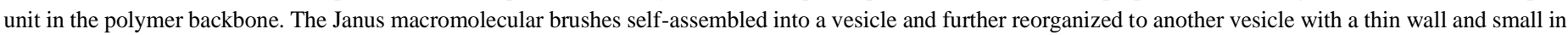

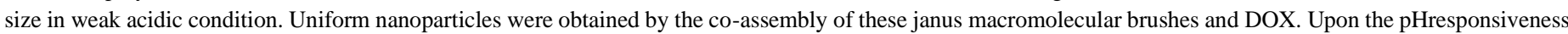

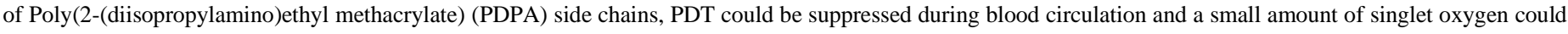

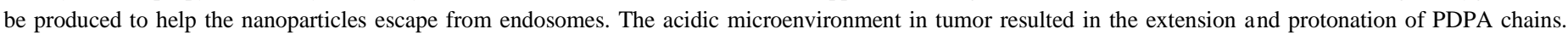

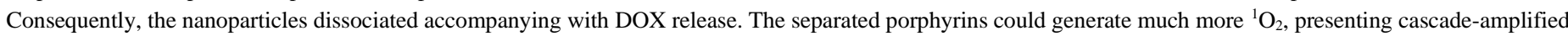

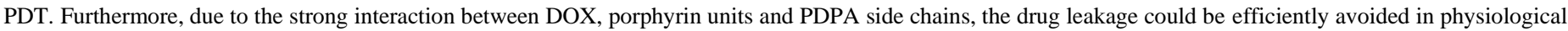

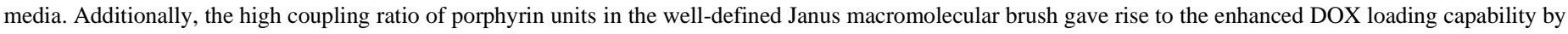

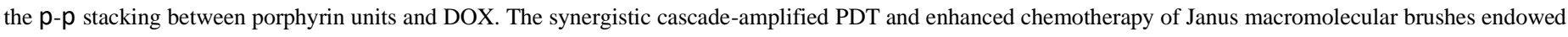
the high phototoxicity and antitumor efficacy, as confirmed by in vitro and in vivo studies.

Despite pH-responsive porphyrin-based block copolymers, our group also developed a ROS-responsive porphyrin-based block copolymers for in situ

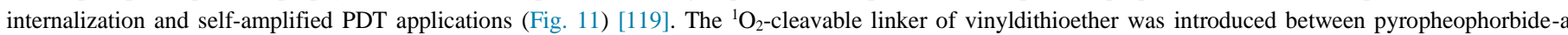

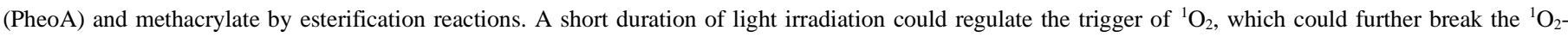

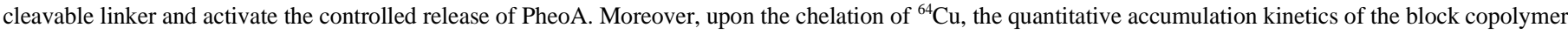

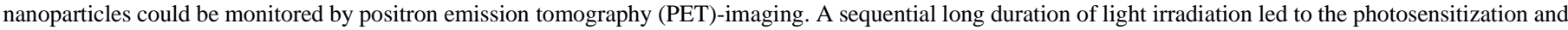
self-amplified PDT. The ${ }^{1} \mathrm{O}_{2}$-responsive block copolymer could provide a new path for the precise manipulation of PDT.

Thus, the construction of porphyrin-based block copolymers can merge the photochemical and photophysical merits of porphyrin units with facile and versatile

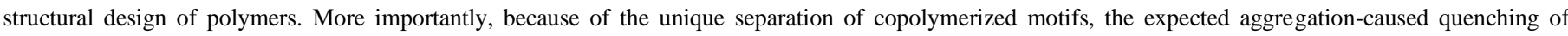

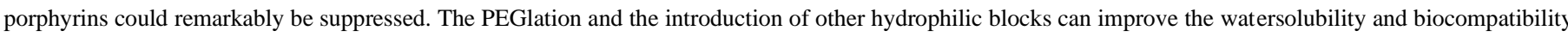

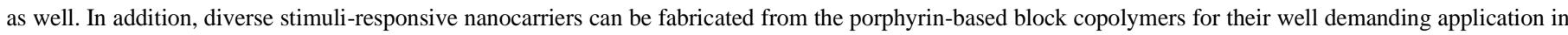
pristine PDT as well as for combination of PDT and chemotherapy. 

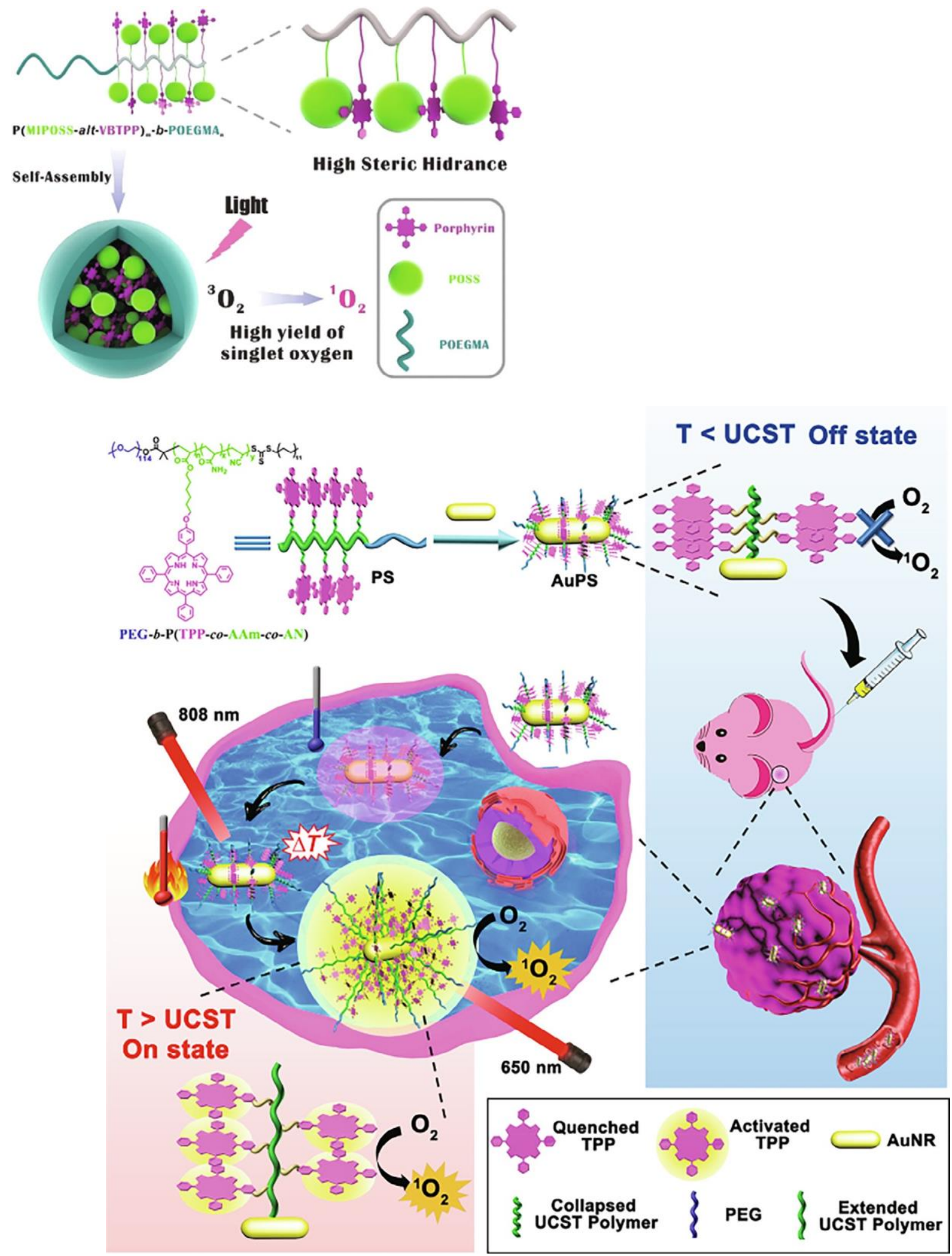

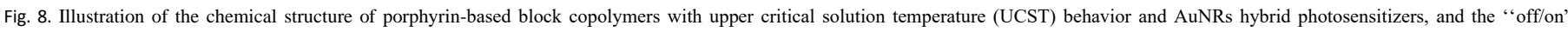
manipulation of PDT. Reprinted with permission of Ref. [116]. Copyright 2019, American Chemical Society.

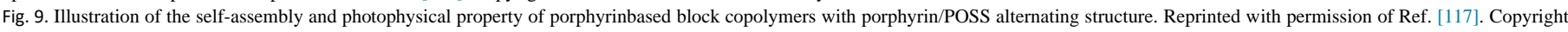
2018 Wiley-VCH Verlag GmbH \& Co. KGaA, Weinheim.

3.2. Porphyrin-based supramolecular polymers in PDT

Supramolecular chemistry refers to the utilization of noncovelent interactions such as van der Waals force, eletrostatic interaction, hydrogen interaction, $p-p$ stacking and hydrophobic interaction to construct supramolecular materials [120,121]. Since the Nobel prize was awarded to Lehn, Cram and Pedersen in 1987 for their investigation of the host-guest chemistry, extensive efforts have been attracted to develop a variety of host-guest systems and to study their applications in solar 
cells, sensors, catalysis and nanomedicines [122-124]. Many macrocycles such as cyclodextrins (CD), pillararenes, cucurbiturils, calixarenes and crown ethers, have been employed as the host molecules. [125127] Zhang and coworkers reported the poineered research work of supramolecular photosensitozers in the ehanced antibacterial PDT. [128,129] Porphyrins with four positive charges were selected as the photosenzitizer and were used as the building block for the construction of supramolecular photosensitizers with cucurbit[7] uril (CB[7]). The positively charged porphyrins benefited the adsorption of photosensitizers onto the negatively charged surface of bacteria via electrostatic attraction. Due to the host-guest interaction, the distance between porphyrins was largely increased. A low porphyrin concentration and short time of light irradiation

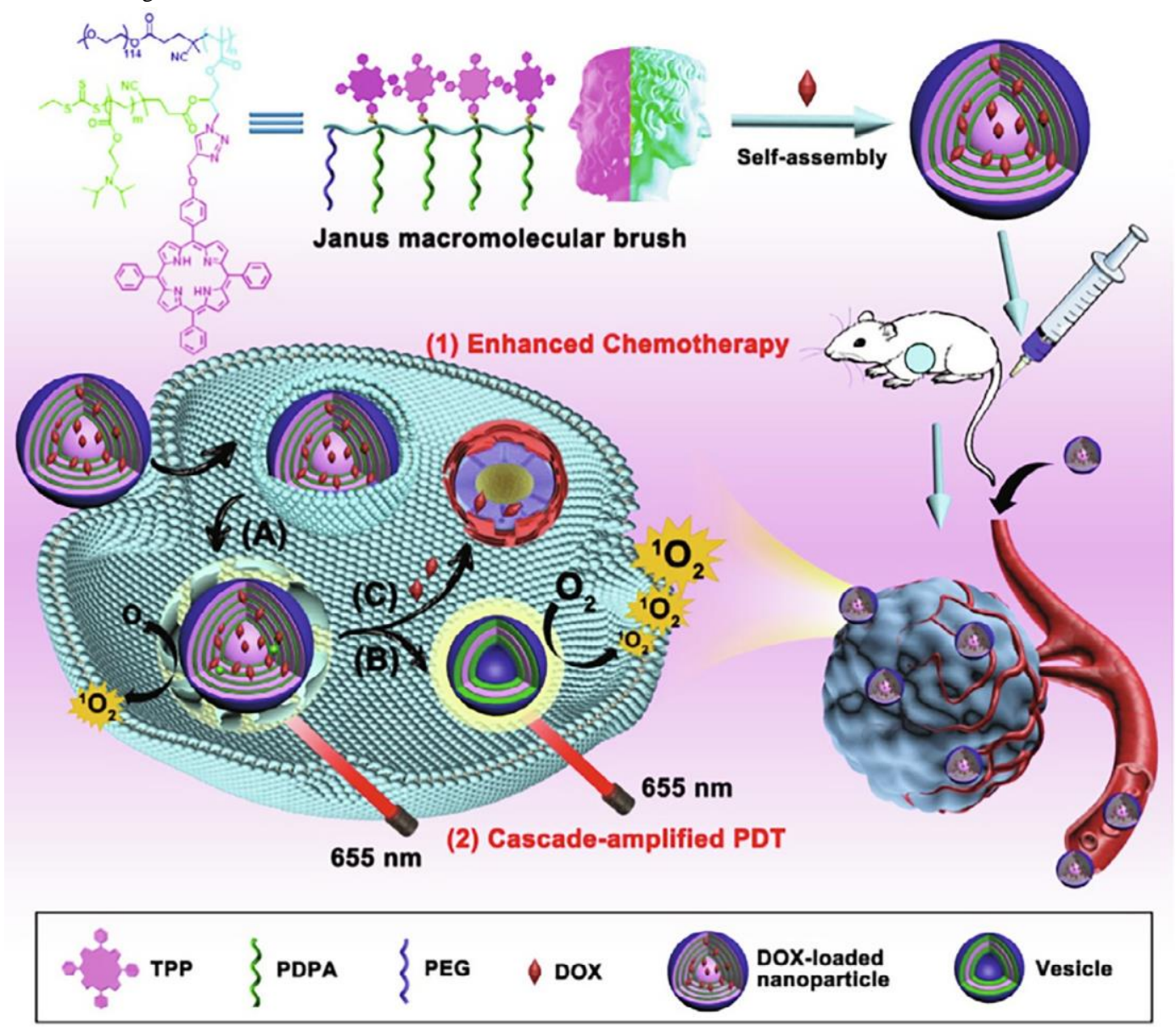

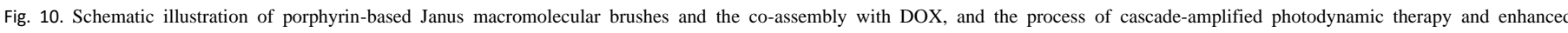
chemotherapy. Reprinted with permission of Ref. [118]. Copyright 2020 Elsevier B.V.

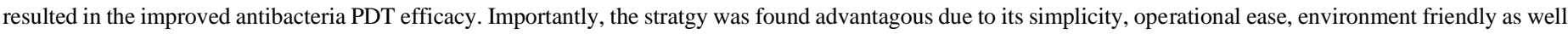
as facile nature.

Supramolecular polymers integrate the intrinsic properties of individual supramolecular chemistry and polymers, which exhibit the stimuli-responsiveness, high revesibility and dynamic properties. [130-133] In this context, diverse supramolecular polymers have been constructed for the utilization in PDT. [134,135] Porphyrins can be coupled with the host or guest molecules and complexed with the complementary motifs. [136] Therefore, a variety of porphyrin-based supramolecular polymers have been fabricated including supramolecular telechelics, block copolymers, comb polymers and star polymers. [137,138] In general, these porphyrin-based hostguest complexes can act as building blocks in porphyrin-based supramolecular polymers either as the coupling junctions in backbones or as conjugates in side chains.

Our group reported the exciting research works of porphyrinbased supramolecular telechelics with b-CD [139] and pillararene [140] as the host motifs in the PDT application (Fig. 12). By esterification and amidation reactions, mono-fuctionalized porphyrin was coupled with disulfide-linked adamantane as the guest motif, and a hydrophilic PEG chain was grafted onto b-CD as the host motif. Upon the host-guest interaction, porphyrin-based telechelics were constructed and further selfassembled into micelles with the size about $85 \mathrm{~nm}$, which could passively accumulate in tumor sites via EPR effect. Particularly, the steric hindrance and natural cavity of b-CD separated the porphyrin units and hence improved the PDT efficiency. It was also found that the GSH-responsiveness of porphyrin-based supramolecular polymers would be activated by the high concentration of GSH in tumor cells after endocytosis.

On the other hand, porphyrins also could be coupled with macrocycles for example pillar[5]arenes (P[5]), to obtain the host motifs (Fig. 13). [140] The complementary pyridine unit could be coupled with a hydrophilic PEG chain of the amphiphile, as a terminal. An amphiphilic supramolecular polymer was obtained by mixing the two parts. Compared with free TPP, an enhanced PDT efficiency of porphyrin-based supramolecular P[5]/pyridine polymers was confirmed by singlet oxygen production by 1,3diphenylisobenzofuran (DPBF) and the cell viability by 3-(4,5-dime thylthiahiazo-2-yl)-2,5-di-phenytetrazoliumromide (MTT) assay.

Moreover, the porphyrin-based host-guest complex also can play the role of monomers in construction of supramolecular polymers. Ji and co-workers constructed the reduction-triggered supramolecular nanocarriers for PDT by the host-guest interaction of CD-modified porphyrin and adamantane-contained zwitterionic polymers (Fig. 14). [141] CD-modified porphyrin was synthesized through carbodiimide reaction. The disulphide bond between the CD and porphyrin could be broke by the high GSH concentration at tumor sites, leading to the reduction-responsive release and activation of porphyrin. 
It is worth noting that, because of the intrinsic hypoxic environment and low light penetration in deep tumor sites, PDT efficiency is very low, that bears the drawback of surviving in-depth cancer cells resulting in tumor recurrence and metastasis. Therefore, the combination of PDT and other therapies including chemotherapy, photothermal therapy, gene therapy and immunotherapy would
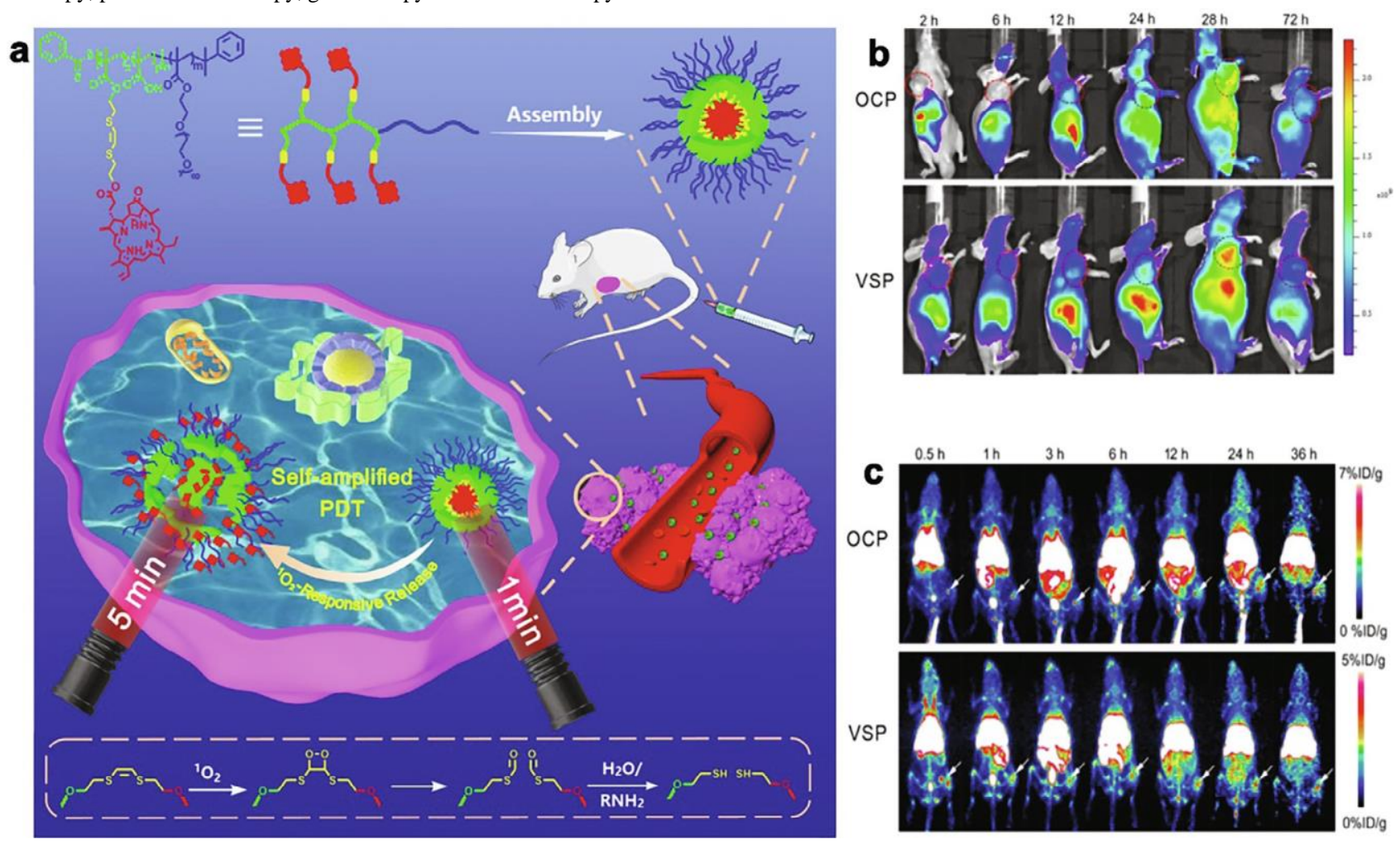

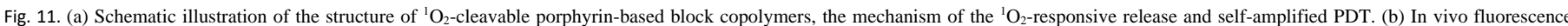
imaging and (c) PET imaging of B16F10 tumor-bearing mice after injecting porphyrin-based block copolymer nanoparticles without (OCP) or with 1

$\mathrm{O}_{2}$-cleavable linkers (VSP) upon different time points. Reprinted with permission of Ref. [119]. Copyright $2020 \mathrm{Wiley-VCH} \mathrm{Verlag} \mathrm{GmbH} \mathrm{\&} \mathrm{Co.} \mathrm{KGaA,} \mathrm{Weinheim.}$

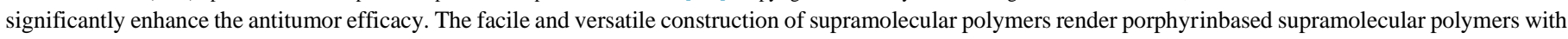

a promising candidate as the nanocarrier for combined therapies. [36]

4. Porphyrin-based metal-organic frameworks in PDT

Metal-organic frameworks (MOFs) are a promising porous crystalline material based on organic ligands and metal containing
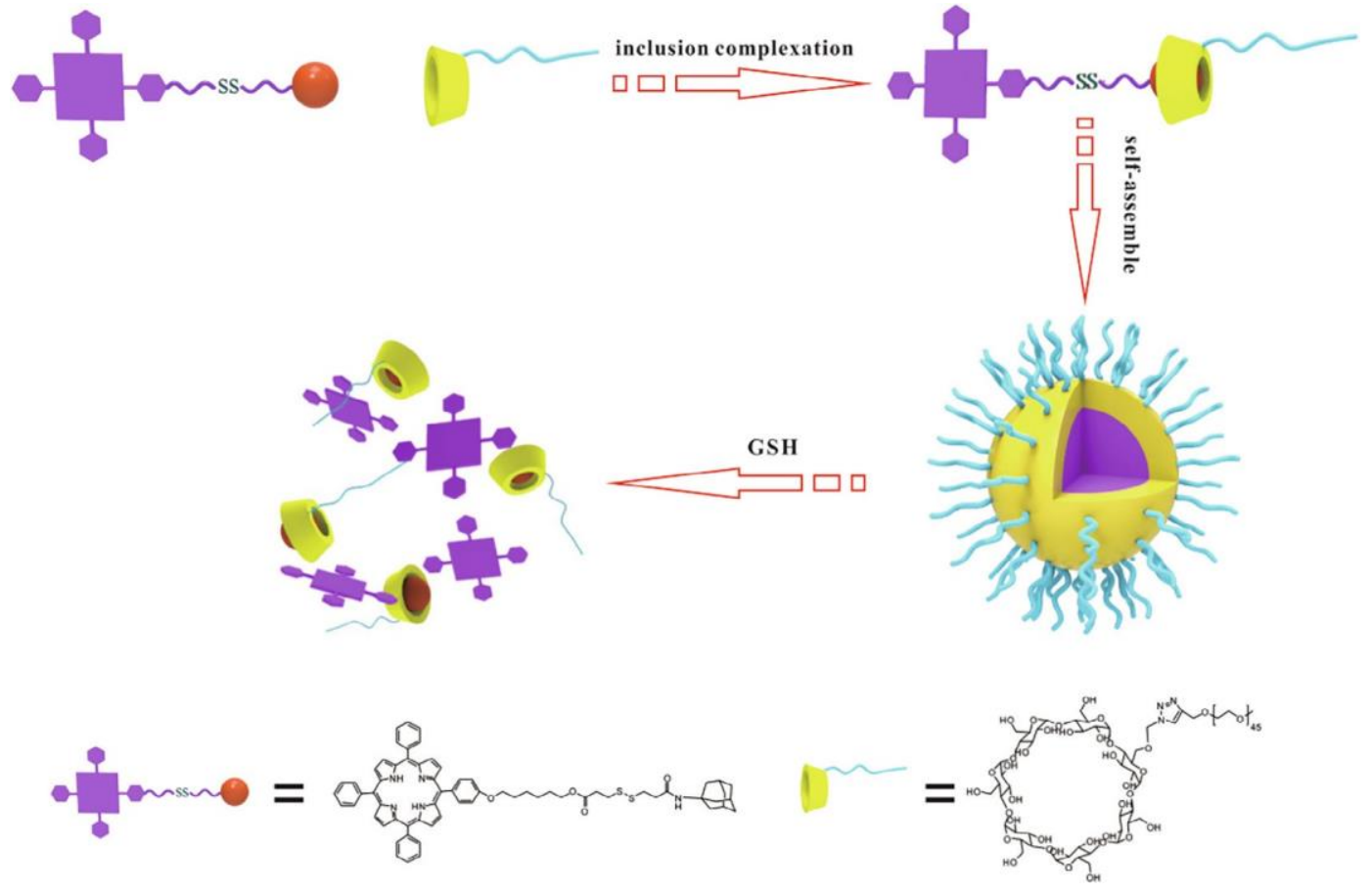


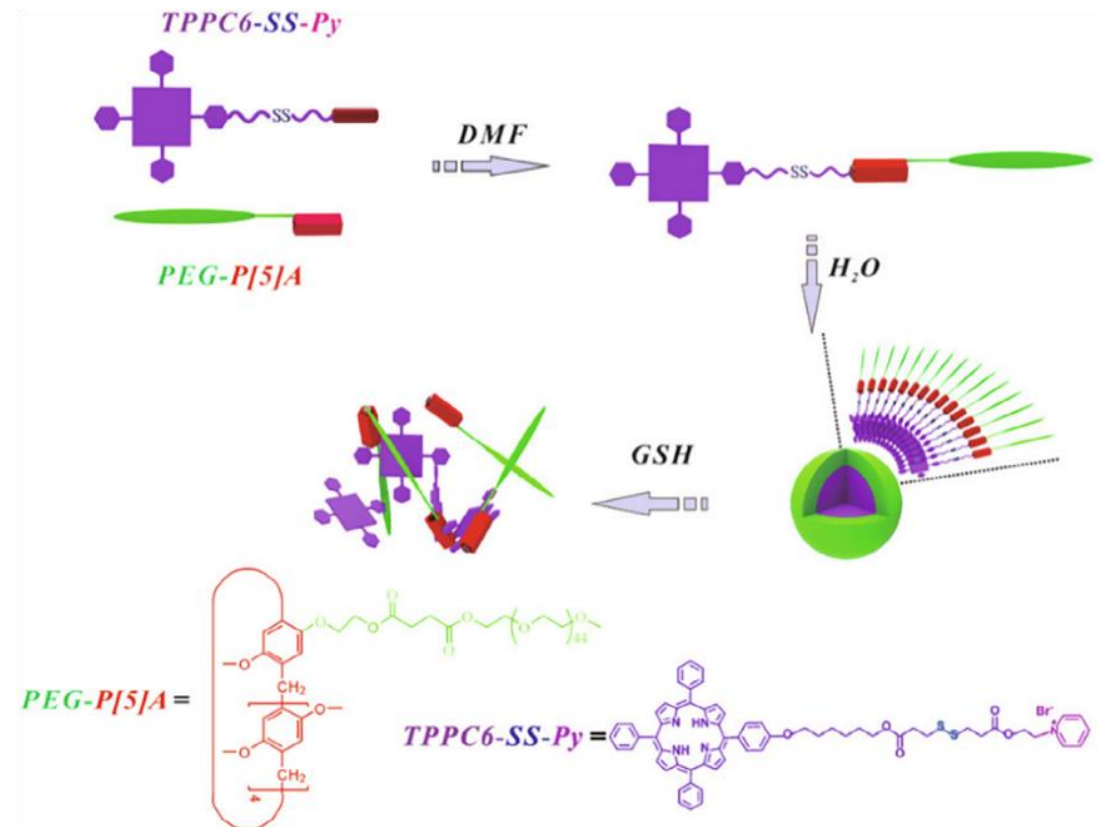

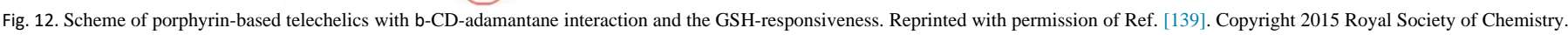

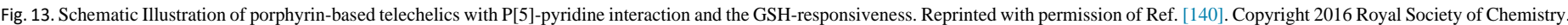

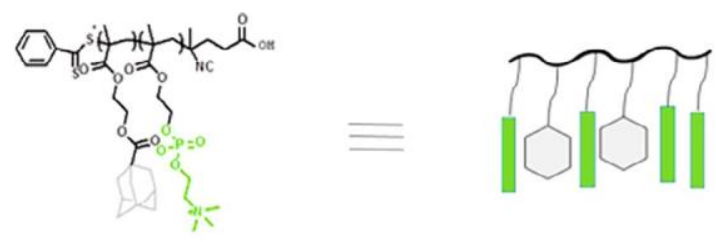

Poly(MPC-co-MAda)

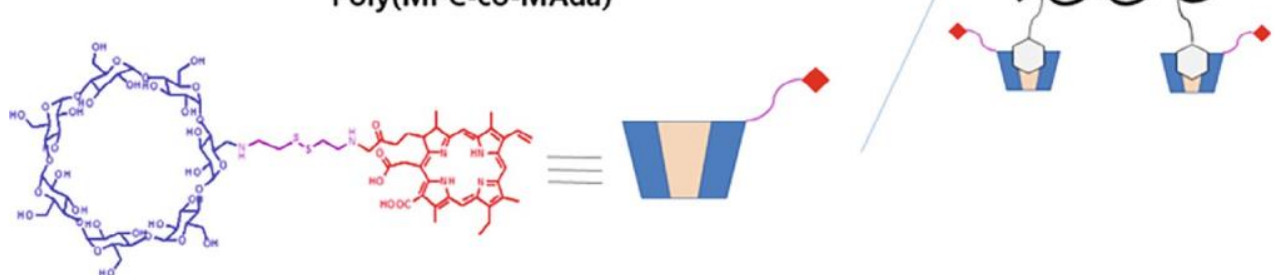

$\beta$-CD-SS-Ce6

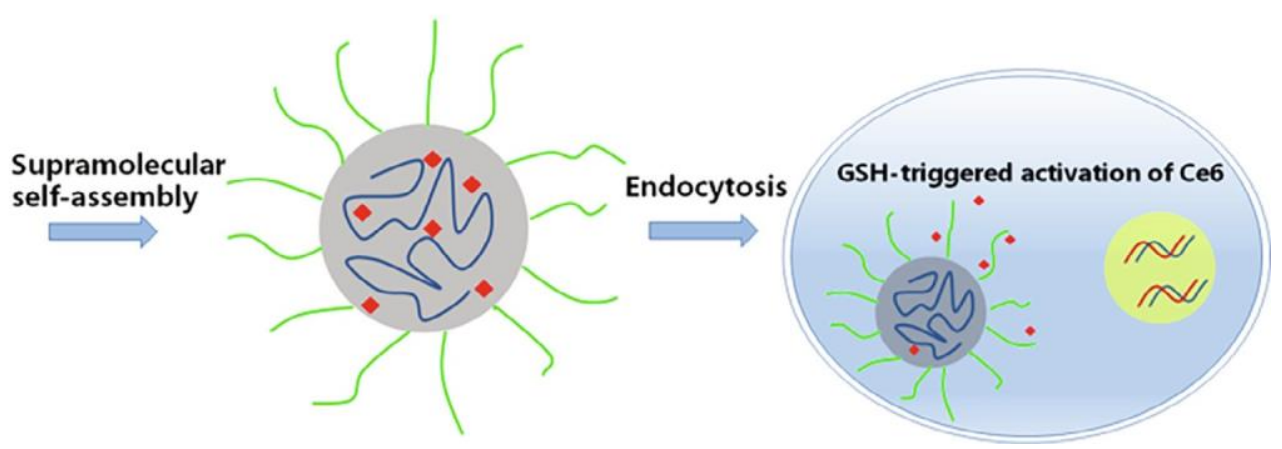

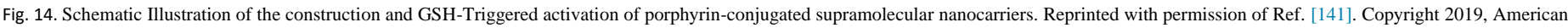
Chemical Society.

node. [142,143] Nanoscaled MOFs have attracted extensive popu- and fucntionalization of nanoscaled MOFs expanded their applicalarity because of their tunable pore structures and sizes, large sur- tions in catalysis, [145,146] biomedicine, [147] and chemical face areas, and good biocompatibility. [144] The facile synthesis adsorption. [148] So far, many MOFs have been developed as drug 

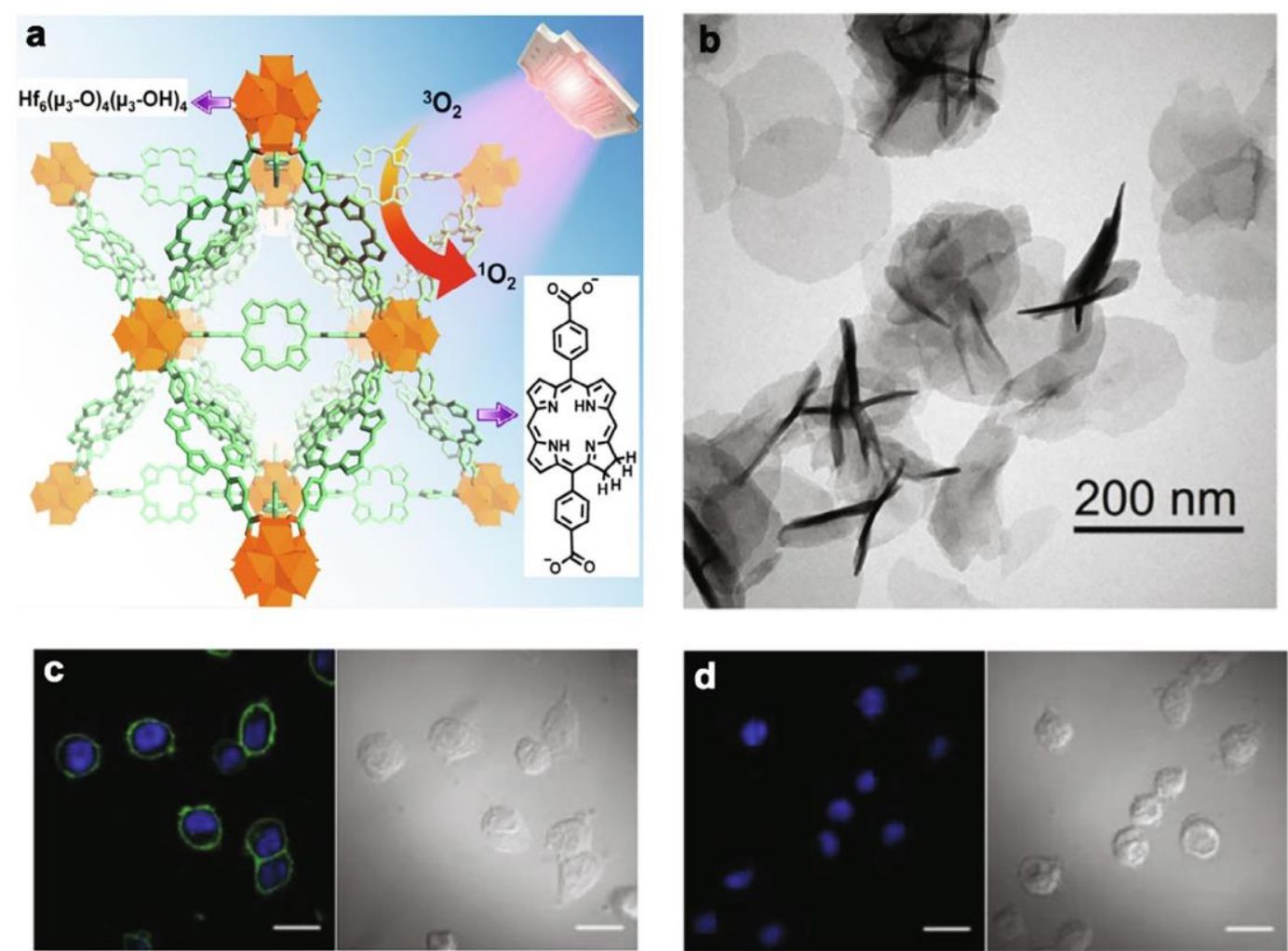

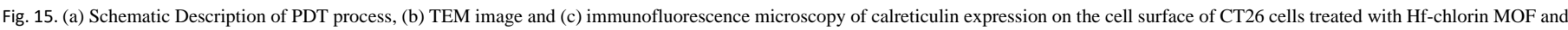

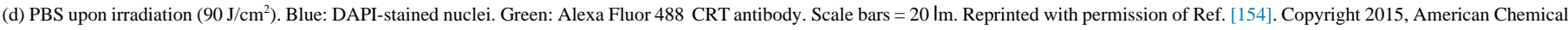
Society.
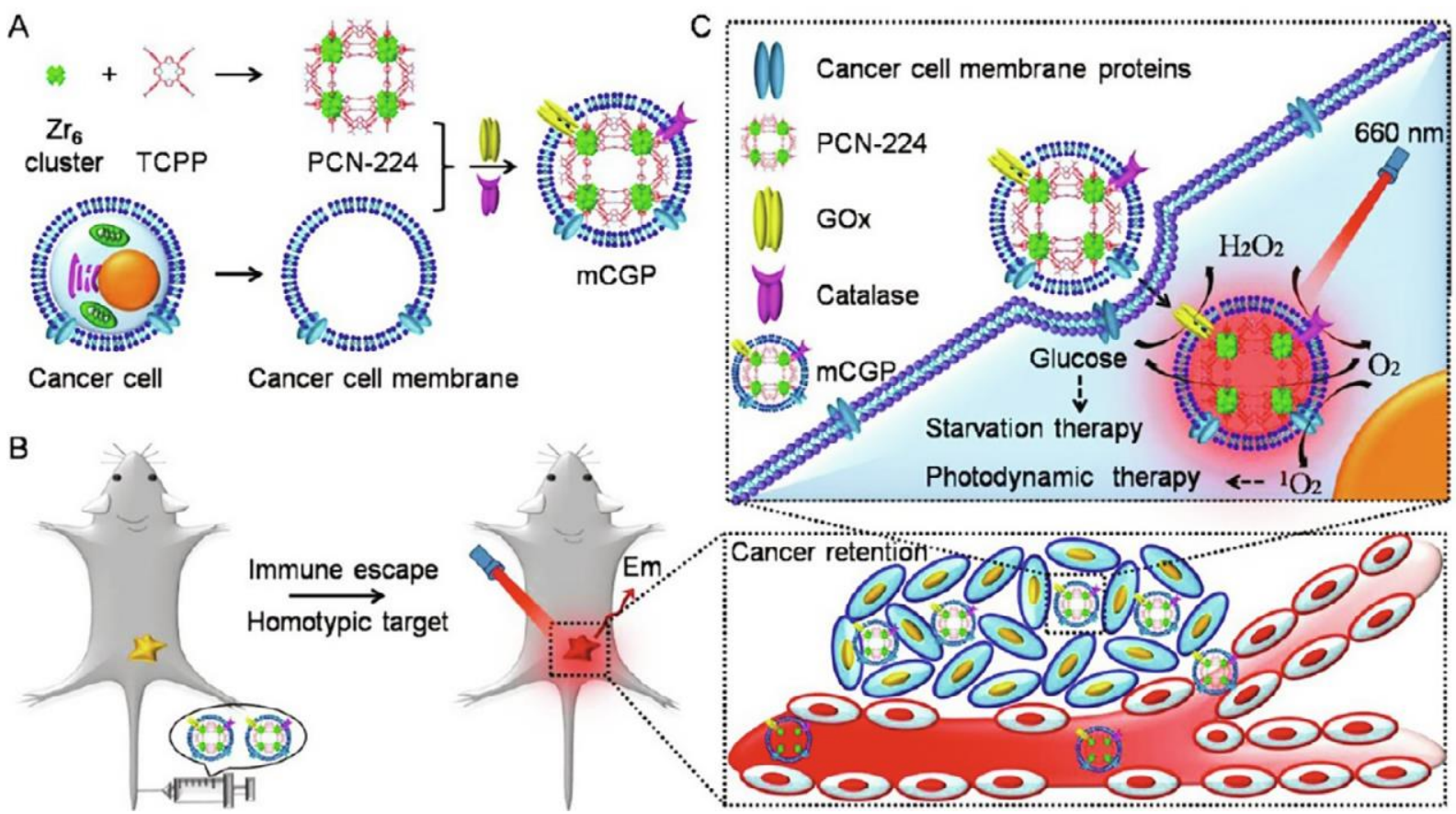

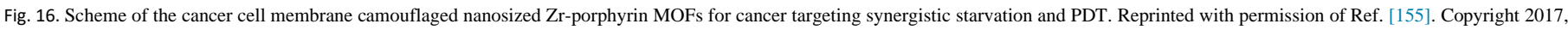
American Chemical Society. 
delivery systems. However, since drug delivery inevitably encoun- promising photosensitizer for enhanced PDT to overcome these ters the severious side effects and drug resistance in chemother- shortcomings of classic drug delivery systems. $[149,150]$ The porapy, porphyrin-based MOFs can provide the opportunities as a phyrinic molecules as the building blocks were directly incorpo-

rated into the MOF structures, leading to the high loading efficiency, avoidable self-quenching and facile diffusion of ROS. [151,152]

Lin and co-workers poineered an early example of Hafnium(Hf)porphyrin MOF as an effective photosensitizer for PDT. [153,154] Hf-porphyrin MOFs exhibited a Universitetet i Oslo (UiO)-type structure and a nanoplate morphology with about $10 \mathrm{~nm}$ in thickness and $100 \mathrm{~nm}$ in diameter. The well-defined framework structure efficiently isolated porphyrins to supress the self-quenching of porphyrins. Furthermore, the strong Hf coordination enhanced the ROS generation by promoting intersystem crossing. [153] In vivo PDT studies illustrated that the porphyrinic UiO MOF exhibited a high tumor eradication to resistant head and neck cancer. Recently, they also reported the construction of the first example of chlorin-based MOF in nanoscale range for PDT of colon cancers (Fig. 15). [154] The chlorid-based MOF demonstrated significant increase in the absorption of Q-band and a $13 \mathrm{~nm}$ bathochromicshift, which induced a deeper light penetration and higher PDT efficiency.

Generally, tetracarboxyl substituted porphyrins could coorperate with $\mathrm{Zr}_{6}$ clusters to construct nanosized Zr-MOF of coordination network-224 (PCN-224). On the basis of the well-defined PCN-224 structure, the Zr-porphyrin MOF can serve as a nanocarrier of both chemotherapeutic drugs and photosensitizers.

Recently, the Zr-porphyrin MOFs were employed to embed enzymes including catalase and glucose oxidase to produce synergistic starvation and robust PDT (Fig. 16). [155] The combination of glucose oxidase and catalase could speed up glucose decomposition to reduce the nutrient supply in tumor site and increase the intracellular oxygen content by catalyzing endogenous $\mathrm{H}_{2} \mathrm{O}_{2}$ to oxygen, which is highly benificial particularly in the hypoxic indepth tumor. Additionally, the cancer cell membrane could be camouflaged on the surface of enzyme-loaded porphyrin-based MOFs to target homotypic and improve the retention abilities due to immune escape. Thus, the fabricated nanosystem played as a cascade bioreactor with enhanced anticancer efficacy by the synergistic starvation therapy and PDT. It presented a promising example of complementary modes in complicated tumor microenviroments.

The unique and versatile functionalities of porphyrin-based MOFs make them the promising nanocarriers for cytotoxic drugs and efficient mediator for PDT, and even the bioimaging agent. However, there are still some drawbacks to overcome before translational step and clinical applications of porphyrin-based MOFs. For example, the weak coordination interactions between metal ions and organic porphyrinic ligands in MOFs led to their dissociation at low pH conditions. In addition, the degradation mechanisms and systemic toxicity of MOFs still demand better and

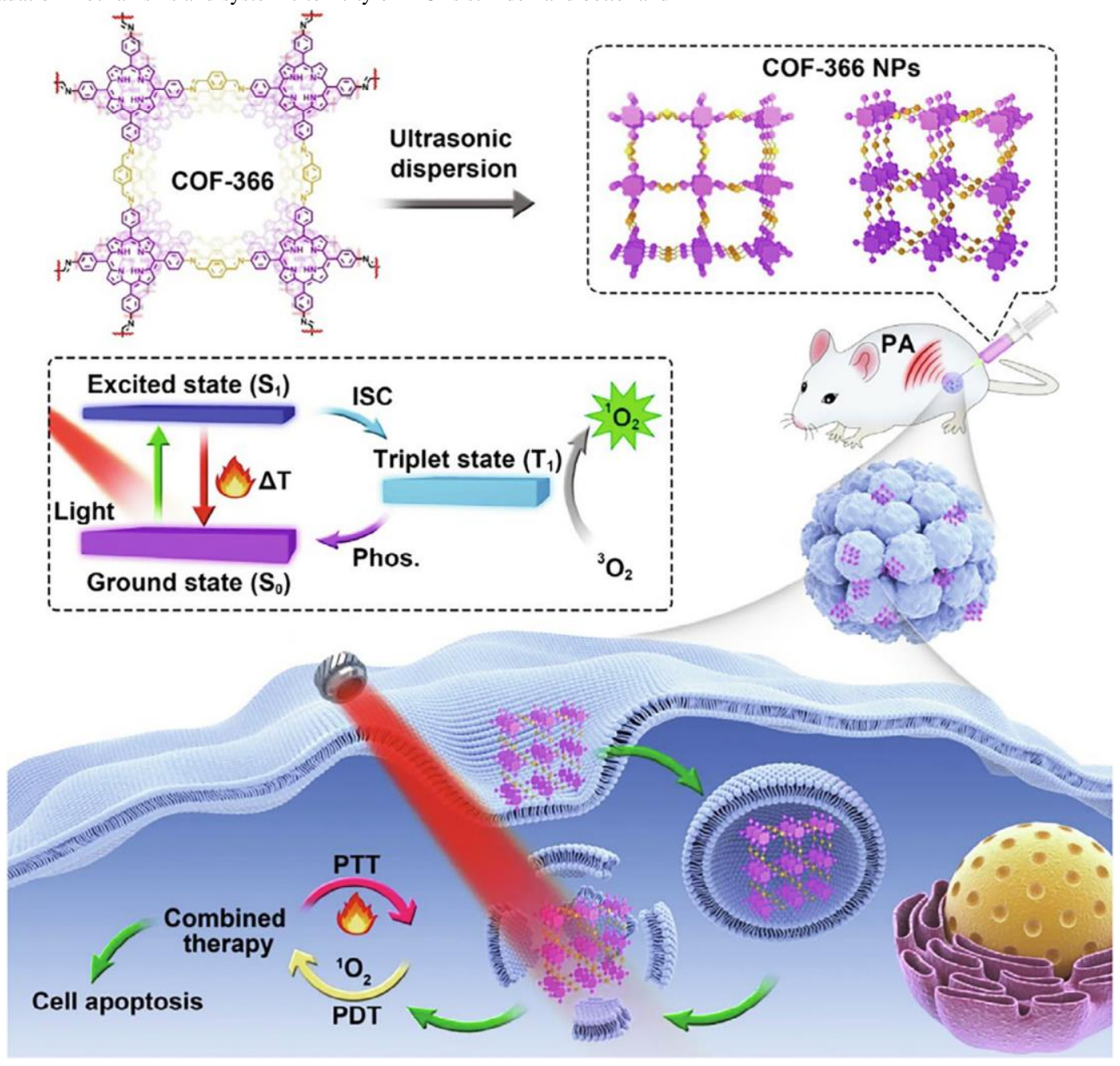

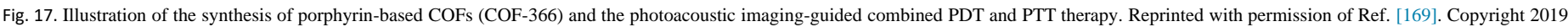
Elsevier B.V. 

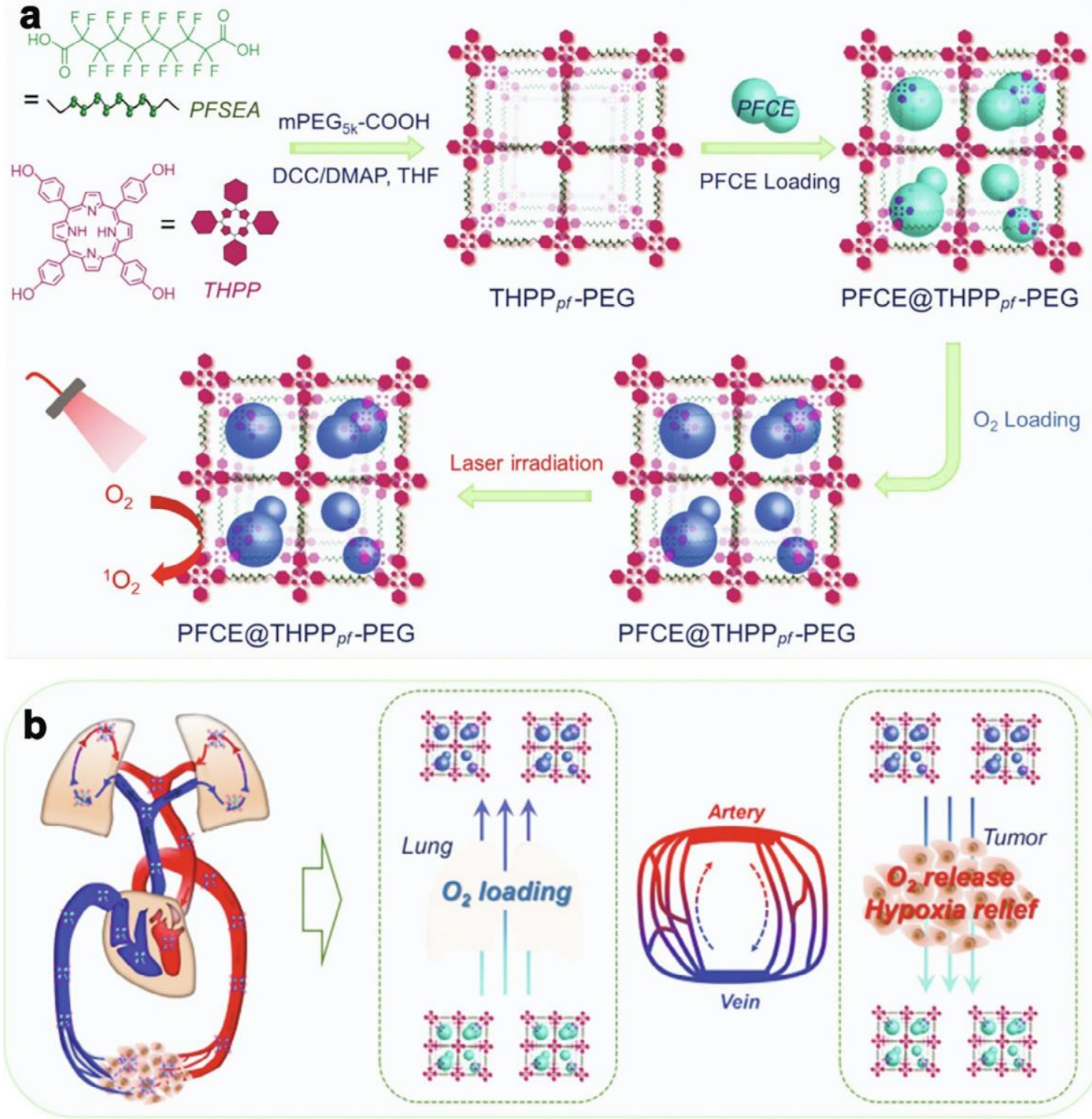

Fig. 18. (a) Illustration of the synthesis route of fluorinated porphyrin-based COFs. (b) Illustration of in vivo tumor oxygenation process. Reprinted with permission of Ref. [171]. Copyright 2018 Wiley-VCH Verlag GmbH \& Co. KGaA, Weinheim.

more comprehensive studies. Although the surface coating of PEG, silica, DNA and proteins has been used to achieve the targeted results with reduced side effects, it is anticipated that more efforts are required for the biosafety, metabolism and excretion of MOFs being used in PDT.

\section{Porphyrin-based covalent-organic frameworks in PDT}

Similar with MOFs, the porous crystalline materials with organic building motifs connected by covalent bonds are defined as covalent organic frameworks (COFs).[156-158] Triazine, boronyl ester, boroxine and imine bonds are generally utilized as the reversible connections for the construction of COFs. [159,160] Because of the planar geometry and rigidity of porphyrins, porphyrinic COFs have attracted much interest in gas adsorption, catalysis, energy harvest, sensing and photochemical applications. [161163] The groups of Yaghi, [164] Jiang [165] and Banerjee [166] have reported several studies detailing the fabrication and applications porphyrin-based COFs for catalysis, optoelectronics, and $\mathrm{CO}_{2}$ reduction.

Recently, porphyrin-based COFs has emerged as an efficient nanomedcine in the biomedical application as well and have dragged increasing research efforts. $[164,167]$ The large inner pores and orderly spatial arrangments of building blocks made them promising candidates for drug release and photodynamic therapy. Lang and co-workers reported an initial study of porphyrinic COFs bearing a 3D diamond-like structure via Schiffbase reaction for the photodynamic antibacterial effect. [168] The 3D porphyrinic COFs possessed not only high local loading concentration of porphyrin, but also the high singlet oxygen yield similar with the TPP molecules in good solvents. More recently, several efforts have been made to synthesis and use the porphyrin-based COFs in antitumor applications. Unfortunately, the size of porphyrin-based COFs is generally too big to be utilized in living organisms. Thus, it is necessary to synthesize the nanosized porphyrin-based COFs for these applications. Chen's group synthesized porphyrin-based COFs (COF-366) with a size of about $100 \mathrm{~nm}$ and used as photoactive agents for photoacoustic (PA) 
imagingguided PDT and PTT combined therapy (Fig. 17). [169] The dynamic reversible and metal-free imine bond endowed porphyrin-based COFs with the degradation capability and enhanced biosafety. The PA-imaging could be used for precise in vivo antitumor treatment. It was evidenced that only single wavelength light irradiation was needed due to the broad absorption of porphyrin-based COFs resulted from their orderly conjugated structure. These porphyrin-based COFs signficantly decreased the self-aggregation and hence the quenching of porphyrin resulting in the enhanced PDT efficacy.

In order to deal with the metabolism problem of COFs, Qu and co-workers reported the construction of porphyrin-based COF nanodots with a renal-clearable ultrasmall size and their usage in PDT for antitumor. [170] The imine linkage was used to connect the building blocks, followed by utilizing a liquid exfoliation strategy for the construction of well-dispersed ultra-small porphyrinbased COF nanodots. PEG coating was further used to enhance the biocompatibility and biostability. The COF nanodots possessed good photodynamic efficiency both in cancer cells treatment and in vivo tumor inhibition because of the high stability, effective tumor accumulation and improved metabolism.

Furthermore, fluorinated porphyrin can also be used as the building blocks in the construction of COFs for the enhanced PDT in the deep tumor hypoxia condition (Fig. 18). [171] One-pot esterification was utilized between perfluorosebacic acid and tetrahydroxylporphyrin to construct fluorinated COFs which could efficiently load perfluoro-15-crown-5-ether and molecular oxygen to improve the tumor oxygenation and the efficiency of PDT antitumor treatment. Efficient tumor accumulation was observed by single-photon emission computed tomography imaging after intravenous injection of a radio-isotope ${ }^{99 \mathrm{~m}} \mathrm{Tc}$ chelated fluorinated porphyrin-based COFs.

\section{Summary and perspectives}

In this review, we provide an overview of recent advances of porphyrin-based functional materials in PDT. We detailed here the PDT applications of different derivatives of porphyrin in association with variaty of materials ranging from amphiphiles to polymers, supramolecular polymers and even 3D nanoparticles to organic frameworks via covalent bonding, reversible dynamic supramolecular interactions and physical encapsulation. The functionalizations significantly improve the watersolubility and biocompatibility of porphyrins. Similarly, the high loading concentration of porphyrins and enhanced PDT efficiency can be achieved from diverse porphyrin-based functional materials.

However, several issues for utilization of porphyrin-based functional materials to their full capacities, need to be addressed in near future. Firstly, the absorption and emission of porphyrinbased materials need to be extended to the longer wavelengths for deeper tissue penetration. Secondly, even with the diverse organic, inorganic or hybrid porphyrin-based materials reported, it is highly desirable to develop more 'intelligent' combined or synergistic therapies to rationally arrange the multiple functions against the specific tumor environment and overcome the inherent limitations of PDT. Thirdly, most of the published research works of porphyrinbased materials mainly focus on basic scientific and fundamental research so far. Hence, Porphyrin-based materials activated by NIR light with good biocompatibility and biodegradability, high photocytoxicity, excellent delivery efficiency in the body and effective tumor targeting with negligible side effects are needed for the translational and clinical PDT practice. We believe that a variety of unique porphyrin-based functional materials would provide more fascinating superiorities in PDT and dramatically expand the potentials and options in cancer treatments. Thus, there is still a long way to go from lab to the patient translation of the findings.

\section{Declaration of Competing Interest}

The authors declare that they have no known competing financial interests or personal relationships that could have appeared to influence the work reported in this paper.

\section{Acknowledgements}

This work was financially supported by the National Natural Science Foundation of China (No. 51803058 and 21875063) and the Fundamental Research Funds for the Central Universities (No. 222201814018).

\section{References}

1. AbdulAlmohsin, S.; Cui, J. B., Graphene-Enriched P3HT and Porphyrin-Modified ZnO Nanowire Arrays for Hybrid Solar Cell Applications. J Phys Chem C 2012, 116 (17), 9433-9438.

2. $\quad$ Abe, S.; Kobayashi, H.; Kiba, T.; Watari, F.; Sato, S. I., Morphology and Photophysical Properties of One-Dimensional Arrayed Porphyrin Aggregates Assisted by Cyclodextrin Inclusion Complexation. Mol Cryst Liq Cryst 2012, 566, 151-157.

3. $\quad$ Alam, M. M.; Bolze, F.; Daniel, C.; Flamigni, L.; Gourlaouen, C.; Heitz, V.; Jenni, S.; Schmitt, J.; Sour, A.; Ventura, B., pi-Extended diketopyrrolopyrrole-porphyrin arrays: one- and two-photon photophysical investigations and theoretical studies. Phys Chem Chem Phys 2016, 18 (31), $21954-$ 21965.

4. Anderson, N. T.; Dinolfo, P. H.; Wang, X., Synthesis and characterization of porphyrin-DNA constructs for the self-assembly of modular energy transfer arrays. J Mater Chem C 2018, 6 (10), 2452-2459.

5. $\quad$ Aratani, N.; Kim, D.; Osuka, A., Discrete Cyclic Porphyrin Arrays as Artificial Light-Harvesting Antenna. Accounts Chem Res 2009, 42 (12), 1922-

1934.

6. $\quad$ Aratani, N.; Osuka, A., Exploration of Giant Functional Porphyrin Arrays. B Chem Soc Jpn 2015, 88 (1), 1-27.

7. $\quad$ Ariga, K.; Hill, J. P.; Wakayama, Y.; Akada, M.; Barrena, E.; de Oteyza, D. G., New aspects of porphyrins and related compounds: self-assembled structures in two-dimensional molecular arrays. J Porphyr Phthalocya 2009, 13 (1), 22-34.

8. $\quad$ Atefi, F.; McMurtrie, J. C.; Arnold, D. P., Multiporphyrin coordination arrays based on complexation of magnesium(II) porphyrins with porphyrinylphosphine oxides. Dalton T 2007, (21), 2163-2170.

9. $\quad$ Baciu, B. C.; de Ara, T.; Sabater, C.; Untiedt, C.; Guijarro, A., Helical nanostructures for organic electronics: the role of topological sulfur in ad hoc synthesized dithia[7]helicenes studied in the solid state and on a gold surface. Nanoscale Adv 2020, 2 (5), 1921-1926.

10. Balogun, S. W.; James, O. O.; Sanusi, Y. K.; Olayinka, O. H., Green synthesis and characterization of zinc oxide nanoparticles using bashful (Mimosa pudica), leaf extract: a precursor for organic electronics applications. Sn Appl Sci 2020, 2 (3).

11. Bearinger, J. P.; Stone, G.; Dugan, L. C.; El Dasher, B.; Stockton, C.; Conway, J. W.; Kuenzler, T.; Hubbell, J. A., Porphyrin-based Photocatalytic Nanolithography A NEW FABRICATION TOOL FOR PROTEIN ARRAYS. Mol Cell Proteomics 2009, 8 (8), 1823-1831. 
12. Bernhard, S. S. R.; Locke, G. M.; Plunkett, S.; Meindl, A.; Flanagan, K. J.; Senge, M. O., Cubane Cross-Coupling and Cubane-Porphyrin Arrays. Chem-Eur J 2018, 24 (5), 1026-1030.

13. Bin, Z. Y.; Liu, Z. Y.; Qiu, Y.; Duan, L., Efficient n-Dopants and Their Roles in Organic Electronics. Adv Opt Mater 2018, 6 (18).

14. Black, C.; Darie, R.; Borton, D., Organic Electronics for Artificial Touch. Trends Neurosci 2018, 41 (9), 568-570.

15. Bouamaied, I.; Nguyen, T.; Ruhl, T.; Stulz, E., Supramolecular helical porphyrin arrays using DNA as a scaffold. Org Biomol Chem 2008, 6 (21), 3888-

16. $\quad$ Bouamaied, I.; Stulz, E., Thieme Chemistry Journal Awardees - Where are They Now? Stabilisation of Porphyrins in Tetranucleotide-Bisporphyrin Arrays by Duplex Formation with Peptide Nucleic Acid. Synlett 2009, (18), 2913-2918.

17. Brennan, B. J.; Durrell, A. C.; Koepf, M.; Crabtree, R. H.; Brudvig, G. W., Towards multielectron photocatalysis: a porphy rin array for lateral hole transfer and capture on a metal oxide surface. Phys Chem Chem Phys 2015, 17 (19), 12728-12734.

18. Brewer, A.; Siligardi, G.; Neylon, C.; Stulz, E., Introducing structural flexibility into porphyrin-DNA zipper arrays (vol 9, pg 777, 2011). Org Biomol Chem 2011, 9 (24), 8505-8506.

19. Brewer, A.; Siligardi, G.; Neylon, C.; Stulz, E., Introducing structural flexibility into porphyrin-DNA zipper arrays. Org Biomol Chem 2011, 9 (3), 777 -

782.

20. Bronshtein, I.; Leitus, G.; Rybtchinski, B., In Situ Growth of High Quality Crystals for Organic Electronics. Acs Appl Electron Ma 2020, 2 (3), $790-795$.

21. Brown, A.; Jeffries-El, M., Towards the development of highly conjugated BDx systems for organic electronics. Abstr Pap Am Chem S 2018, 256.

22. $\quad$ Bruce, R. C.; Wang, R. B.; Rawson, J.; Therien, M. J.; You, W., Valence Band Dependent Charge Transport in Bulk Molecular Electronic Devices Incorporating Highly Conjugated Multi-[(Porphinato)Metal] Oligomers. J Am Chem Soc 2016, 138 (7), 2078-2081.

23. Buchner, F.; Seufert, K.; Auwarter, W.; Heim, D.; Barth, J. V.; Flechtner, K.; Gottfried, J. M.; Steinruck, H. P.; Marbach, H., NO-Induced Reorganization of Porphyrin Arrays. Acs Nano 2009, 3 (7), 1789-1794.

24. Zhang, J. X.; Wu, Y.; Liu, J. C.; Li, R. Z., Bilayer structured supramolecular light harvesting arrays based on zinc porphy rin coordination polymers for enhanced photocurrent generation in dye sensitized solar cells. Dalton T 2016, 45 (41), 16283-16289.

25. Zhang, L. J.; Jiang, X. X.; Jiang, W.; Li, S.; Chi, Y. X.; Liu, H.; Zhang, M. Y.; Li, J. Y.; Fang, M.; Pan, B.; Chen, Y. L.; Shen, C. N.; Guo, X.; Li, R.; Guo, L.; Su, Y. W., Infrared Skin-Like Active Stretchable Electronics Based on Organic-Inorganic Composite Structures for Promotion of Cutaneous Wound Healing. Adv Mater Technol-Us 2019, 4 (8).

26. Zhang, S. M.; Kim, J. O.; Li, Y. J.; Wen, B.; Zhou, M. B.; Liu, S. B.; Aratani, N.; Xu, L.; Kim, D.; Song, J. X., meso-to-meso 2,5-Pyrrolylene bridged zig-zag porphyrin arrays. Chem Commun 2017, 53 (83), 11488-11491.

27. Zhang, X. N.; Wang, B. H.; Huang, L. Z.; Huang, W.; Wang, Z.; Zhu, W. G.; Chen, Y.; Mao, Y. L.; Facchetti, A.; Marks, T. J., Breath figurederived porous semiconducting films for organic electronics. Sci Adv 2020, 6 (13).

28. Zhang, X. T.; Dong, H. L.; Hu, W. P., Organic Semiconductor Single Crystals for Electronics and Photonics. Adv Mater 2018, 30 (44).

29. Zhao, P.; Zhu, L. L., Virtual special issue: Organic and polymer materials for electronics. Chinese Chem Lett 2018, 29 (12), $1706-1708$.

30. Zhao, Q. D.; Yu, M.; Xie, T. F.; Peng, L. L.; Wang, P.; Wang, D. J., Photovoltaic properties of a ZnO nanorod array affected by ethanol and liquidcrystalline porphyrin. Nanotechnology 2008, 19 (24).

31. Zhao, Z. X.; Cammidge, A. N.; Cook, M. J., Towards black chromophores: mu-oxo linked phthalocyanine-porphyrin dyads and phthalocyaninesubphthalocyanine dyad and triad arrays. Chem Commun 2009, (48), 7530-7532.

32. Zhu, P. H.; Wang, P. P.; Kan, T. L.; Sun, G. Q.; Zhang, Y.; Yu, J. H., An enhanced photoelectrochemical immunosensing platform: Supramolecular donor-acceptor arrays by assembly of porphyrin and C-60. Biosens Bioelectron 2015, 68, 604-610.

33. Zhu, T.; Zheng, L. Y.; Yi, C.; Yu, T. Z.; Cao, Y.; Liu, L.; Gong, X., Two-Dimensional Conjugated Polymeric Nanocrystals for Organic Electronics. Acs Appl Electron Ma 2019, 1 (8), 1458-1464.

34. Zvezdin, A.; Di Mauro, E.; Rho, D.; Santato, C.; Khalil, M., En route toward sustainable organic electronics. Mrs Energy Sustain 2020, 7.

35. Bullard, G.; Tassinari, F.; Ko, C. H.; Mondal, A. K.; Wang, R.; Mishra, S.; Naaman, R.; Therien, M. J., Low-Resistance Molecular Wires Propagate Spin-Polarized Currents. J Am Chem Soc 2019, 141 (37), 14707-14711.

36. Pinkerton, N. M.; Gindy, M. E.; Calero-DdelC, V. L.; Wolfson, T.; Pagels, R. F.; Adler, D.; Gao, D. Y.; Li, S. K.; Wang, R. B.; Zevon, M.; Yao, N.; Pacheco, C.; Therien, M. J.; Rinaldi, C.; Sinko, P. J.; Prud'homme, R. K., Single-Step Assembly of Multimodal Imaging Nanocarriers: MRI and LongWavelength Fluorescence Imaging. Adv Healthc Mater 2015, 4 (9), 1376-1385.

37. Teo, R. D.; Wang, R. B.; Smithwick, E. R.; Migliore, A.; Therien, M. J.; Beratan, D. N., Mapping hole hopping escape routes in proteins. P Natl Acad Sci USA 2019, 116 (32), 15811-15816.

38. Wang, R. B.; Brugh, A. M.; Rawson, J.; Therien, M. J.; Forbes, M. D. E., Alkyne-Bridged Multi[Copper(II) Porphyrin] Structures: Nuances of Orbital Symmetry in Long-Range, Through-Bond Mediated, Isotropic Spin Exchange Interactions. J Am Chem Soc 2017, 139 (29), $9759-9762$.

39. Wang, R. B.; Ko, C. H.; Brugh, A. M.; Bai, Y. S.; Forbes, M. D. E.; Therien, M. J., Topology, Distance, and Orbital Symmetry Effects on Electronic Spin-Spin Couplings in Rigid Molecular Systems: Implications for Long-Distance Spin-Spin Interactions. J Phys Chem A 2020, 124 (37), $7411-7415$.

40. Zhang, C. F.; Chen, M.; Qian, D. J., Characterization and electrochemistry of interfacial self-assembled multi-manganese (III)-porphyrin arrays. Thin Solid Films 2009, 517 (13), 3760-3765.

41. Goodenough, I.; Rawson, J.; Angiolillo, P.; Therien, M., Charge accommodation in n-doped ethynyl-bridged pi-conjugated porphyrin arrays. Abstr Pap Am Chem $S$ 2016, 252.

42. $\quad$ Calvo, J. J.; Angel, S. M.; So, M. C., Charge transport in metal-organic frameworks for electronics applications. Apl Mater 2020, 8 (5).

43. Paolesse, R.; Lvova, L.; Nardis, S.; Di Natale, C.; D'Amico, A.; Lo Castro, F., Chemical images by porphyrin arrays of sensors. Microchim Acta 2008, $163(1-2), 103-112$.

44. Cho, W. J.; Cho, Y.; Min, S. K.; Kim, W. Y.; Kim, K. S., Chromium Porphyrin Arrays As Spintronic Devices. J Am Chem Soc 2011, 133 (24), $9364-$

9369.

45. Lee, M.; Kim, H.; Kim, D.; Sim, E., Coherence length determination of meso-meso linked porphyrin arrays based on forward-backward pair trajectory analysis. J Phys Chem A 2008, 112 (23), 5040-5045.

46. Lee, M.; Kim, H.; Kim, D.; Sim, E., Coherent excitation energy transfer of meso-meso linked porphyrin array. 2007 Pacific Rim Conference on Lasers and Electro-Optics, Vols 1-4 2007, 1388-1389.

47. Liu, Y.; Ke, C. F.; Zhang, H. Y.; Cui, J.; Ding, F., Complexation-induced transition of nanorod to network aggregates: Alternate porphyrin and cyclodextrin arrays. J Am Chem Soc 2008, 130 (2), 600-605.

48. Magna, G.; Catini, A.; Kumar, R.; Palmacci, M.; Martinelli, E.; Paolesse, R.; di Natale, C., Conductive Photo-Activated Porphyrin-ZnO

Nanostructured Gas Sensor Array. Sensors-Basel 2017, 17 (4).

49. Wang, M.; Baek, P.; Akbarinejad, A.; Barker, D.; Travas-Sejdic, J., Conjugated polymers and composites for stretchable organic electronics. $J$ Mater Chem C 2019, 7 (19), 5534-5552.

50. Tanaka, T.; Osuka, A., Conjugated porphyrin arrays: synthesis, properties and applications for functional materials. Chem Soc Rev 2015, 44 (4), 943-969 51. Crossley, M. J.; Sheehan, C. S.; Khoury, T.; Reimers, J. R.; Sintic, P. J., Construction of building blocks for extended porphyrin arrays by nitration of porphyrin-2,3-diones and quinoxalino[2,3-b]porphyrins. New J Chem 2008, 32 (2), 340-352. 
52. Iritani, K.; Tahara, K.; Hirose, K.; De Feyter, S.; Tobe, Y., Construction of cyclic arrays of Zn-porphyrin units and their guest binding at the solid-liquid interface. Chem Commun 2016, 52 (100), 14419-14422.

53. Hutchison, J. A.; Sintic, P. J.; Brotherhood, P. R.; Scholes, C.; Blake, I. M.; Ghiggino, K. P.; Crossley, M. J., Control of Photoinduced Charge Transfer Lifetimes in Porphyrin Arrays by Ligand Addition. J Phys Chem C 2009, 113 (27), 11796-11804.

54. $\quad$ Ma, L. C.; Dai, S. X.; Zhan, X. W.; Liu, X. Y.; Li, Y., Convenient fabrication of conjugated polymer semiconductor nanotubes and their application in organic electronics. Roy Soc Open Sci 2018, 5 (8).

55. Trinh, T. M. N.; Nierengarten, I.; Ben Aziza, H.; Meichsner, E.; Holler, M.; Chesse, M.; Abidi, R.; Bijani, C.; Coppel, Y.; Maisonhaute, E.; Delavaux-Nicot, B.; Nierengarten, J. F., Coordination-Driven Folding in Multi-Zn-II-Porphyrin Arrays Constructed on a Pillar[5]arene Scaffold. Chem-Eur J 2017, $23(46), 11011-11021$

56. Capuano, R.; Pomarico, G.; Paolesse, R.; Di Natale, C., Corroles-Porphyrins: A Teamwork for Gas Sensor Arrays. Sensors-Basel 2015, 15 (4), 8121-

8130.

57. Nakamura, Y.; Aratani, N.; Osuka, A., Cyclic porphyrin arrays as artificial photosynthetic antenna: Synthesis and excitation energy transfer. Chem Soc Rev 2007, 36 (6), 831-845.

58. Muftakhov, M. V.; Khatymov, R. V.; Tuktarov, R. F., Decomposition of Aromatic Compounds Relevant to Organic Electronics under Exposure to LowEnergy Electrons. Tech Phys+ 2018, 63 (12), 1854-1860

59. Yang, J. S.; Yoo, H.; Aratani, N.; Osuka, A.; Kim, D., Determination of the Superradiance Coherence Length of Directly Linked Linear Porphyrin Arrays at the Single-Molecule Level. Angew Chem Int Edit 2009, 48 (24), 4323-4327.

60. Ham, S.; Lee, J. E.; Song, S.; Peng, X. B.; Hori, T.; Aratani, N.; Osuka, A.; Sim, E.; Kim, D., Direct observation of structural properties and fluorescent trapping sites in macrocyclic porphyrin arrays at the single-molecule level. Phys Chem Chem Phys 2016, 18 (5), $3871-3877$.

61. Song, C. H.; Back, S. Y.; Yu, S. I.; Lee, H. J.; Kim, B. S.; Yang, N. Y.; Jeong, S. H.; Ahn, H., Direct-Patterning of Porphyrin Dot Arrays and Lines Using Electrohydrodynamic Jet Printing. J Nanosci Nanotechno 2012, 12 (1), 475-480.

62. Fendt, L. A.; Bouamaied, I.; Thoni, S.; Amiot, N.; Stulz, E., DNA as supramolecular scaffold for porphyrin arrays on the nanorneter scale. J Am Chem Soc 2007, 129 (49), 15319-15329.

63. Payne, A. J.; Rice, N. A.; McAfee, S. M.; Lo, S.; Josse, P.; Cabanetos, C.; Risko, C.; Lessard, B. H.; Welch, G. C., Donor or Acceptor? How Selection of the Rylene Imide End Cap Impacts the Polarity of pi-Conjugated Molecules for Organic Electronics. Acs Appl Energ Mater 2018, 1 (9), $4906-4916$.

64. Fujimoto, J.; Manseki, K.; Miyaji, H., Dye-sensitized Solar Cells Using Supramolecular Porphyrin Arrays Inspired by pi-Stacking Structures of Photosynthetic Light-harvesting Complexes. Chem Lett 2014, 43 (2), 207-209.

65. Luo, L.; Lin, C. J.; Tsai, C. Y.; Wu, H. P.; Li, L. L.; Lo, C. F.; Lin, C. Y.; Diau, E. W. G., Effects of aggregation and electron injection on photovoltaic performance of porphyrin-based solar cells with oligo(phenylethynyl) links inside $\mathrm{TiO} 2$ and $\mathrm{Al} 2 \mathrm{O} 3$ nanotube arrays. Phys Chem Chem Phys 2010, 12 (5), 1064-1071.

66. Sugawa, K.; Yamaguchi, D.; Tsunenari, N.; Uchida, K.; Tahara, H.; Takeda, H.; Tokuda, K.; Jin, S.; Kusaka, Y.; Fukuda, N.; Ushijima, H.; Akiyama, T.; Watanuki, Y.; Nishimiya, N.; Otsuki, J.; Yamada, S., Efficient Photocurrent Enhancement from Porphyrin Molecules on Plasmonic Copper Arrays: Beneficial Utilization of Copper Nanoanntenae on Plasmonic Photoelectric Conversion Systems. Acs Appl Mater Inter 2017, 9 (1), 750-762.

67. Ouyang, Q.; Zhu, Y. Z.; Zhang, C. H.; Yan, K. Q.; Li, Y. C.; Zheng, J. Y., An Efficient PIFA-Mediated Synthesis of Fused Diporphyrin and TriplySingly Interlacedly Linked Porphyrin Array. Org Lett 2009, 11 (22), 5266-5269.

68. Souto, M.; Strutynski, K.; Melle-Franco, M.; Rocha, J., Electroactive Organic Building Blocks for the Chemical Design of Functional Porous Frameworks (MOFs and COFs) in Electronics. Chem-Eur J 2020.

69. Tabbi, G.; Di Mauro, G.; Purrello, R.; Bonomo, R. P., Electrochemical characterization of ordered arrays of metallo-porphyrins in aqueous solution Dalton T 2011, 40 (16), 4223-4229.

70. $\quad$ Kim, J.; Yamamoto, K.; Iimura, S.; Ueda, S.; Hosono, H., Electron Affinity Control of Amorphous Oxide Semiconductors and Its Applicability to Organic Electronics. Adv Mater Interfaces 2018, 5 (23).

71. Cho, S.; Yoon, M. C.; Kim, K. S.; Kim, P.; Kim, D., Electron delocalization in various triply linked zinc(II) porphyrin arrays: role of antiaromatic junctions between aromatic porphyrins. Phys Chem Chem Phys 2011, 13 (36), 16175-16181.

72. $\quad$ Rawson, J.; Angiolillo, P. J.; Frail, P. R.; Goodenough, I.; Therien, M. J., Electron Spin Relaxation of Hole and Electron Polarons in pi-Conjugated Porphyrin Arrays: Spintronic Implications. J Phys Chem B 2015, 119 (24), 7681-7689.

73. Lazarides, T.; Kuhri, S.; Charalambidis, G.; Panda, M. K.; Guldi, D. M.; Coutsolelos, A. G., Electron vs Energy Transfer in Arrays Featuring Two Bodipy Chromophores Axially Bound to a Sn(IV) Porphyrin via a Phenolate or Benzoate Bridge. Inorg Chem 2012, 51 (7), $4193-4204$.

74. High, J. S.; Virgil, K. K.; Jakubikova, E., Electronic Structure and Absorption Properties of Strongly Coupled Porphyrin-Perylene Arrays. J Phys Chem A 2015, 119 (38), 9879-9888.

75. Jiang, H.; Hu, W. P., The Emergence of Organic Single-Crystal Electronics. Angew Chem Int Edit 2020, 59 (4), $1408-1428$

76. Novikov, A. V.; Kuznetsova, L. I.; Dremova, N. N.; Parfenov, A. A.; Troshin, P. A., Environment-friendly aqueous processing of [60]fullerene semiconducting films for truly green organic electronics. J Mater Chem C 2020, 8 (2), 495-499.

77. Li, J. L.; Cao, J. J.; Duan, L. L.; Zhang, H. L., Evolution of Isoindigo-Based Electron-Deficient Units for Organic Electronics: From Natural Dyes to Organic Semiconductors. Asian J Org Chem 2018, 7 (11), 2147-2160.

78. Rawson, J.; Angiolillo, P. J.; Therien, M. J., Exceptional delocalization of electrons in conjugated porphyrin arrays. Abstr Pap Am Chem S 2012, 244.

79. Yang, J.; Park, M.; Yoon, Z. S.; Hori, T.; Peng, X. B.; Aratani, N.; Dedecker, P.; Hotta, J. I.; Uji-I, H.; Sliwa, M.; Hofkens, J.; Osuka, A.; Kim, D., Excitation energy migration processes in cyclic porphyrin Arrays probed by single molecule spectroscopy. J Am Chem Soc 2008, 130 (6), $1879-1884$.

80. Kim, P.; Ikeda, T.; Lim, J. M.; Park, J.; Lim, M.; Aratani, N.; Osuka, A.; Kim, D., Excited-state energy relaxation dynamics of triply linked Zn(II) porphyrin arrays. Chem Commun 2011, 47 (15), 4433-4435.

81. Kim, T.; Oh, J.; Jiang, H. W.; Tanaka, T.; Osuka, A.; Kim, D., Exciton coupling dynamics in syn- and anti-type beta-beta linked Zn(II) porphyrin linear arrays. Phys Chem Chem Phys 2016, 18 (33), 23105-23110.

82. Hori, T.; Nakamura, Y.; Aratani, N.; Osuka, A., Exploration of electronically interactive cyclic porphyrin arrays. J Organomet Chem 2007, 692 (1-3), $148-155$.

83. Titi, H. M.; Nandi, G.; Tripuramallu, B. K.; Goldberg, I., Exploring Supramolecular Self-Assembly of Tetraarylporphyrins by Halogen Interactions. 3. $\operatorname{Tin}(\mathrm{L})(2)(\mathrm{A}(2) \mathrm{B}(2)$-Porphyrin) Arrays Supported by Concerted Halogen and Hydrogen Bonding. Cryst Growth Des 2015, 15 (6), $3063-3075$.

84. Luzanov, A. V., Extended quasi-correlated orbitals with long-range effects: Application to organic single-molecule electronics. Funct Mater 2020, 27 (1), $147-158$.

85. $\quad$ Sugawa, K.; Uchida, K.; Takeshima, N.; Jin, S.; Tsunenari, N.; Takeda, H.; Kida, Y.; Akiyama, T.; Otsuki, J.; Takase, K.; Yamada, S., Extraordinary enhancement of porphyrin photocurrent utilizing plasmonic silver arrays. Nanoscale 2016, 8 (34), 15467-15472.

86. Sanchez-Vergara, M. E.; Guevara-Martinez, E.; Arreola-Castillo, A.; Mendoza-Sevilla, A., Fabrication of Hybrid Membranes Containing Nylon-11 and Organic Semiconductor Particles with Potential Applications in Molecular Electronics. Polymers-Basel 2020, 12 (1).

87. La, D. D.; Thi, H. P. N.; Kim, Y. S.; Rananaware, A.; Bhosale, S. V., Facile fabrication of Cu(II)-porphyrin MOF thin films from tetrakis(4carboxyphenyl) porphyrin and $\mathrm{Cu}(\mathrm{OH})(2)$ nanoneedle array. Appl Surf Sci 2017, 424, 145-150. 
88. Slodek, A.; Zych, D.; Maron, A.; Golba, S.; Schab-Balcerzak, E.; Janeczek, H.; Siwy, M.; Mackowski, S., Fluorene vs carbazole substituent at quinoline core toward organic electronics. Dyes Pigments 2019, 166, 98-106.

89. Kose, K.; Motoyanagi, J.; Kusukawa, T.; Osuka, A.; Tsuda, A., Formation of Discrete Ladders and a Macroporous Xerogel Film by the Zipperlike Dimerization of Meso-Meso-Linked Zinc(II) Porphyrin Arrays with Di(pyrid-3-yl)acetylene. Angew Chem Int Edit 2015, 54 (30), 8673-8678.

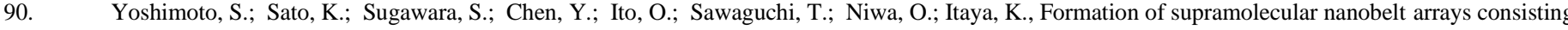
of cobalt(II) "Picket-Fence" porphyrin on Au surfaces. Langmuir 2007, 23 (2), 809-816.

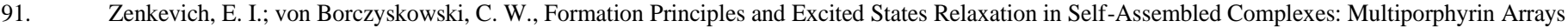
and "Semiconductor CdSe/ZnS Quantum Dot-Porphyrin" Nanocomposites. Handb Porphyr Sci 2012, 22, $67-168$.

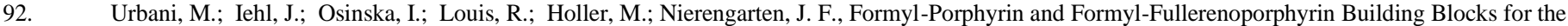
Construction of Multiporphyrin Arrays. Eur J Org Chem 2009, (22), 3715-3725.

93. Sariciftci, N. S., From Organic Electronics to Bio-organic Electronics. Nonlinear Opt Quantu 2019, 50 (1-3), 137-144.

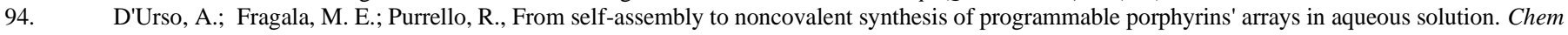
Commun 2012, 48 (66), 8165-8176.

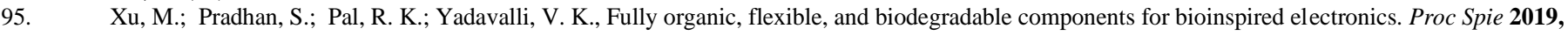

10982.

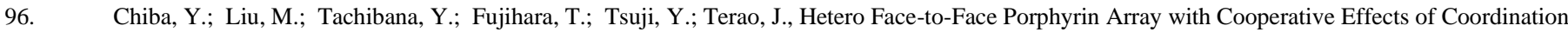
and Host-Guest Complexation. Chem-Asian J 2017, 12 (15), 1900-1904.

97. Lo, P. C.; Leng, X. B.; Ng, D. K. P., Hetero-arrays of porphyrins and phthalocyanines. Coordin Chem Rev 2007, 251 (17-20), $2334-2353$.

98. Yoon, M. C.; Yoon, Z. S.; Cho, S.; Kim, D.; Takagi, A.; Matsumoto, T.; Kawai, T.; Hori, T.; Peng, X. B.; Aratani, N.; Osuka, A., A hexagonal prismatic porphyrin array: Synthesis, STM detection, and efficient energy hopping in near-infrared region. J Phys Chem A 2007, 111 (38), $9233-9239$.

99. Gumyusenge, A.; Mei, J. G., High Temperature Organic Electronics. Mrs Adv 2020, 5 (10), $505-513$.

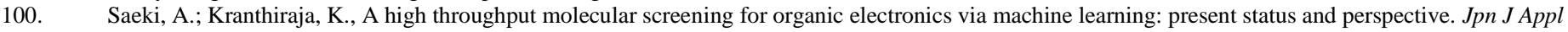
Phys 2020, 59 .

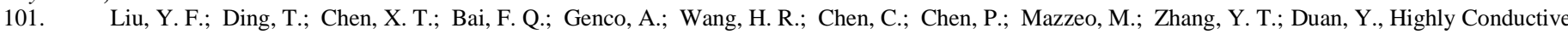
Alkaline-Earth Metal Electrodes: The Possibility of Maintaining Both Low Work Function and Surface Stability for Organic Electronics. Adv Opt Mater 2020.

102. Yang, C.; Liu, Q. F.; Zang, L. M.; Qiu, J. H.; Wang, X.; Wei, C.; Qiao, X.; Hu, L.; Yang, J.; Song, G.; Liu, C. J., High-Performance Yarn Supercapacitor Based on Metal-Inorganic-Organic Hybrid Electrode for Wearable Electronics. Adv Electron Mater 2019, 5 (1).

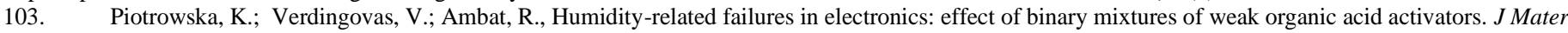
Sci-Mater El 2018, 29 (20), 17834-17852.

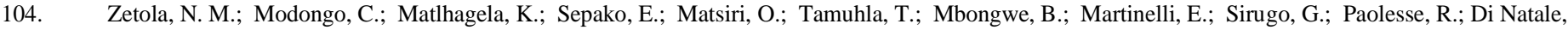
C., Identification of a Large Pool of Microorganisms with an Array of Porphyrin Based Gas Sensors. Sensors-Basel 2016, 16 (4).

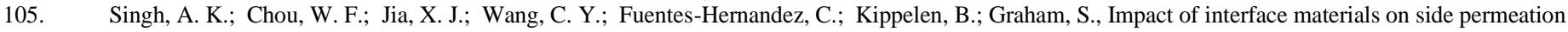
in indirect encapsulation of organic electronics. J Vac Sci Technol A 2020, 38 (3).

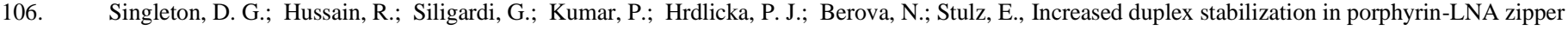
arrays with structure dependent exciton coupling. Org Biomol Chem 2016, 14 (1), 149-157.

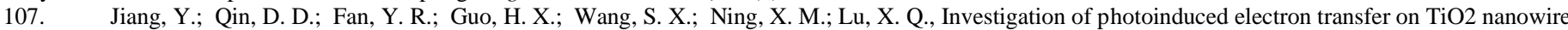
arrays/porphyrin composite via scanning electrochemical microscopy. Rsc Adv 2015, 5 (70), 56697-56703.

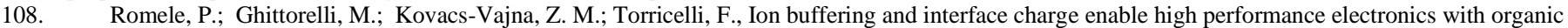
electrochemical transistors. Nat Commun 2019, 10.

109. Muresan, A. Z.; Holten, D.; Bocian, D. F.; Lindsey, J. S., Isotopically labeled porphyrins for studies of ground-state hole transfer in multiporphyrin arrays. Abstr Pap Am Chem S 2007, 234

110. Kozaki, M.; Uetomo, A.; Suzuki, S.; Okada, K., A Light-Harvesting Array Composed of Porphyrins and Rigid Backbones. Org Lett 2008, 10 (20), 4477-4480.

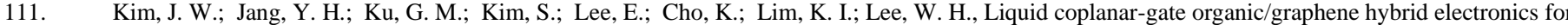
label-free detection of single and double-stranded DNA molecules. Org Electron 2018, 62, 163-167.

112. Vollbrecht, J.; Oechsle, P.; Stepen, A.; Hoffmann, F.; Paradies, J.; Meyers, T.; Hilleringmann, U.; Schmidtke, J.; Kitzerow, H., Liquid crystalline dithienothiophene derivatives for organic electronics. Org Electron 2018, 61, 266-275.

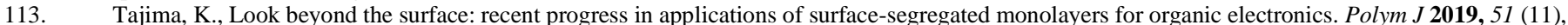

1117-1126

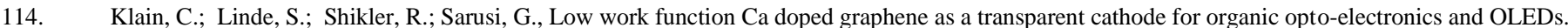
Carbon 2020, 157, 255-261.

115. Peng, X. B.; Huang, Y. Y.; Gao, C.; Peng, J. B.; Komatsu, N.; Osuka, A.; Cao, Y., Macroscopic Films of Porphyrin Nanowell-Arrays via Solvent Diffusion-Induced Self-Assembly. J Phys Chem C 2010, 114 (43), 18449-18454.

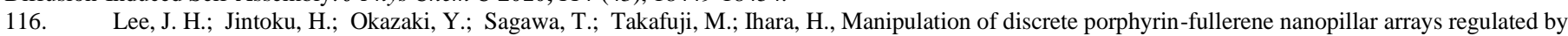
the phase separated infiltration of polymer in ternary blended organic thin-films. Sol Energ Mat Sol C 2015, 140, 428-438.

117. Mitra, K. Y.; Alalawe, A.; Voigt, S.; Boeffel, C.; Baumann, R. R., Manufacturing of All Inkjet-Printed Organic Photovoltaic Cell Arrays and Evaluating Their Suitability for Flexible Electronics. Micromachines-Basel 2018, 9 (12).

118. Emandi, G.; Shaker, Y. M.; Flanagan, K. J.; O'Brien, J. M.; Senge, M. O., Merging Triptycene, BODIPY and Porphyrin Chemistry: Synthesis and Properties of Mono- and Trisubstituted Triptycene Dye Arrays. Eur J Org Chem 2017, (45), 6680-6692.

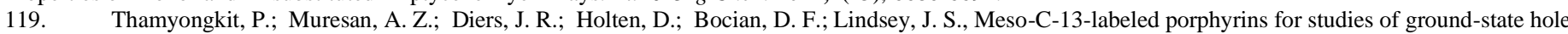
transfer in multiporphyrin arrays. J Org Chem 2007, 72 (14), 5207-5217.

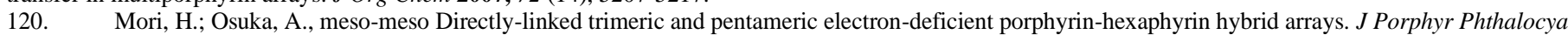
2016, 20 (1-4), 245-253

121. Mori, H.; Tanaka, T.; Lee, S.; Lim, J. M.; Kim, D.; Osuka, A., meso-meso Linked Porphyrin-[26]Hexaphyrin-Porphyrin Hybrid Arrays and Their Triply Linked Tapes Exhibiting Strong Absorption Bands in the NIR Region. J Am Chem Soc 2015, 137 (5), $2097-2106$.

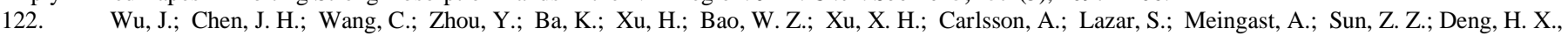
Metal-Organic Framework for Transparent Electronics. Adv Sci 2020, 7 (8).

123. Yu, J. X.; Mathew, S.; Flavel, B. S.; Quinton, J. S.; Johnston, M. R.; Shapter, J. G., Mixed assembly of ferrocene/porphyrin onto carbon nanotube arrays towards multibit information storage. 2008 International Conference on Nanoscience and Nanotechnology 2008, 176-179.

124. Santi, S.; Rossi, S., Molecular design of star-shaped benzotrithiophene materials for organic electronics. Tetrahedron Lett 2019, 60 (36).

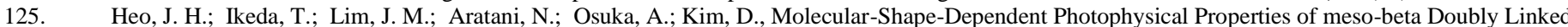

Zn(II) Porphyrin Arrays and Their Indene-Fused Analogues. J Phys Chem B 2010, 114 (45), 14528-14536.

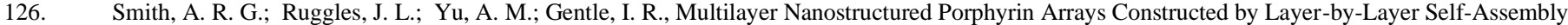
Langmuir 2009, 25 (17), 9873-9878. 
127. He, Z. R.; Zhang, Z. Y.; Bi, S., Nanoparticles for organic electronics applications. Mater Res Express 2020, 7 (1).

128. Cao, J.; Hu, D. C.; Liu, J. C.; Li, R. Z.; Jin, N. Z., Nanostructured TiO2 modified with acetohydrazide zinc porphyrin well-arrays for supramolecular solar cells. Org Electron 2014, 15 (2), 509-516.

129. Nowak-Krol, A.; Shoyama, K.; Stolte, M.; Wurthner, F., Naphthalene and perylene diimides - better alternatives to fullerenes for organic electronics? Chem Commun 2018, 54 (98), 13763-13772.

130. Caironi, M.; Muller, C.; von Hauff, E.; Sommer, M., New Materials for Organic Electronics: Improved Properties to Tackle Application Challenges. Adv Electron Mater 2018, 4 (10).

131. Korzec, M.; Kotowicz, S.; Rzycka-Korzec, R.; Schab-Balcerzak, E.; Malecki, J. G.; Czichy, M.; Lapkowski, M., Novel beta-ketoenamines versus azomethines for organic electronics: characterization of optical and electrochemical properties supported by theoretical studies. J Mater Sci 2020, 55 (9), 3812-3832.

132. Yutronkie, N. J.; Grant, T. M.; Melville, O. A.; Lessard, B. H.; Brusso, J. L., Old Molecule, New Chemistry: Exploring Silicon Phthalocyanines as Emerging N-Type Materials in Organic Electronics. Materials 2019, 12 (8).

133. Pirotte, G.; Verstappen, P.; Vanderzande, D.; Maes, W., On the "True" Structure of Push-Pull-Type Low-Bandgap Polymers for Organic Electronics. Adv Electron Mater 2018, 4 (10).

134. Ragni, R.; Punzi, A.; Babudri, F.; Farinola, G. M., Organic and Organometallic Fluorinated Materials for Electronics and Optoelectronics: A Survey on Recent Research. Eur J Org Chem 2018, 2018 (27-28), 3500-3519.

135. Goswami, S.; Goswami, S.; Venkatesan, T., An organic approach to low energy memory and brain inspired electronics. Appl Phys Rev 2020, 7 (2).

136. Sinha, S.; Li, Z.; Noh, Y.; Chon, K.; Cao, Y.; Sotzing, G., Organic conductive polymers as printed electronics on fabrics for wearable electronics. Abstr Pap Am Chem S 2019, 257.

137. Wang, Y.; Sun, L. J.; Wang, C.; Yang, F. X.; Ren, X. C.; Zhang, X. T.; Dong, H. L.; Hu, W. P., Organic crystalline materials in flexible electronics. Chem Soc Rev 2019, 48 (6), 1492-1530.

138. Seck, M.; Mohammadian, N.; Diallo, A. K.; Faraji, S.; Erouel, M.; Bouguila, N.; Ndiaye, D.; Khirouni, K.; Majewski, L. A., Organic FETs using biodegradable almond gum as gate dielectric: A promising way towards green electronics. Org Electron 2020, 83.

139. Ling, H. F.; Liu, S. H.; Zheng, Z. J.; Yan, F., Organic Flexible Electronics. Small Methods 2018, 2 (10).

140. Yu, K.; Rich, S.; Lee, S.; Fukuda, K.; Yokota, T.; Someya, T., Organic Photovoltaics: Toward Self-Powered Wearable Electronics. P Ieee 2019, 107 (10), 2137-2154.

141. Lau, W. Y.; Hopkins, M., Organized arrays of functional molecules supported by gallium-porphyrin monolayers on HOPG. Abstr Pap Am Chem S 2015,

249 .

142. He, W. L.; Fang, F.; Ma, D. M.; Chen, M.; Qian, D. J.; Liu, M. H., Palladium-directed self-assembly of multi-titanium(IV)-porphyrin arrays on the substrate surface as sensitive ultrathin films for hydrogen peroxide sensing, photocurrent generation, and photochromism of viologen. Appl Surf Sci 2018, 427, 10031010 .

143. Hu, G. F.; Liu, R.; Alexy, E. J.; Mandal, A. K.; Bocian, D. F.; Holten, D.; Lindsey, J. S., Panchromatic chromophore-tetrapyrrole light-harvesting arrays constructed from Bodipy, perylene, terrylene, porphyrin, chlorin, and bacteriochlorin building blocks. New J Chem 2016, 40 (9), $8032-8052$.

144. Ji, D. Y.; Li, T.; Fuchs, H., Patterning and applications of nanoporous structures in organic electronics. Nano Today $2020,31$.

145. Sakaguchi, K.; Kamimura, T.; Uno, H.; Mori, S.; Ozako, S.; Nobukuni, H.; Ishida, M.; Tani, F., Phenothiazine-Bridged Cyclic Porphyrin Dimers as

High-Affinity Hosts for Fullerenes and Linear Array of C-60 in Self-Assembled Porphyrin Nanotube. J Org Chem 2014, 79 (7), $2980-2992$.

146. Popere, B. C.; Sanoja, G. E.; Thomas, E. M.; Schauser, N. S.; Jones, S. D.; Bartels, J. M.; Helgeson, M. E.; Chabinyc, M. L.; Segalman, R. A.,

Photocrosslinking polymeric ionic liquids via anthracene cycloaddition for organic electronics. J Mater Chem C 2018, 6 (32), $8762-8769$.

147. de Tacconi, N. R.; Chanmanee, W.; Rajeshwar, K.; Rochford, J.; Galoppini, E., Photoelectrochemical Behavior of Polychelate Porphyrin

Chromophores and Titanium Dioxide Nanotube Arrays for Dye-Sensitized Solar Cells. J Phys Chem C 2009, 113 (7), 2996-3006.

148. Yoon, M. C.; Noh, S. B.; Tsuda, A.; Nakamura, Y.; Osuka, A.; Kim, D., Photophysics of meso-beta doubly linked Ni(II) porphyrin arrays: Large twophoton absorption cross-section and fast energy relaxation dynamics. J Am Chem Soc 2007, 129 (33), 10080-+.

149. Johnson, J. A.; Lin, Q. P.; Wu, L. C.; Obaidi, N.; Olson, Z. L.; Reeson, T. C.; Chen, Y. S.; Zhang, J., A "pillar-free", highly porous

metalloporphyrinic framework exhibiting eclipsed porphyrin arrays. Chem Commun 2013, 49 (27), 2828-2830.

150. Mao, Y. Y.; Zhao, Q.; Pan, T. T.; Shi, J. Y.; Jiang, S. M.; Chen, M. W.; Zhou, B. P.; Tian, Y. Q., Platinum porphyrin/3-

(trimethoxysily)propylmethacrylate functionalized flexible PDMS micropillar arrays as optical oxygen sensors. New J Chem 2017, 41 (13), $5429-5435$.

151. Wu, Y.; Liu, Y.; Emrick, T.; Russell, T. P., Polymer design to promote low work function surfaces in organic electronics. Prog Polym Sci 2020, 103.

152. Yamamura, T.; Suzuki, S.; Taguchi, T.; Onoda, A.; Kamachi, T.; Okura, I., Porphyrin Arrays Responsive to Additives. Fluorescence Tuning. J Am Chem Soc 2009, 131 (33), 11719-11726.

153. Ryan, A.; Gehrold, A.; Perusitti, R.; Pintea, M.; Fazekas, M.; Locos, O. B.; Blaikie, F.; Senge, M. O., Porphyrin Dimers and Arrays. Eur J Org Chem 2011, (29), 5817-5844.

154. Endo, M.; Fujitsuka, M.; Majima, T., Porphyrin light-harvesting arrays constructed in the recombinant tobacco mosaic virus scaffold. Chem-Eur J 2007, $13(31), 8660-8666$.

155. Liu, Q. Y.; Zhu, J. Q.; Sun, T.; Zhou, H. Y.; Shao, Q.; Li, G. J.; Liu, X. D.; Yin, Y. S., Porphyrin nanotubes composed of highly ordered molecular arrays prepared by anodic aluminum template method. Rsc Adv 2013, 3 (8), 2765-2769.

156. Lvova, L.; Di Natale, C.; Paolesse, R., Porphyrin-based chemical sensors and multisensor arrays operating in the liquid phase. Sensor Actuat B-Chem 2013, 179, 21-31.

157. Maretina, I. A., Porphyrin-Ethynyl Arrays: Synthesis, Design, and Application. Russ J Gen Chem+ 2009, 79 (7), $1544-1581$.

158. Shirsat, M. D.; Sarkar, T.; Kakoullis, J.; Myung, N. V.; Konnanath, B.; Spanias, A.; Mulchandani, A., Porphyrin-Functionalized Single-Walled Carbon Nanotube Chemiresistive Sensor Arrays for VOCs. J Phys Chem C 2012, 116 (5), 3845-3850.

159. Chen, J. P.; Aratani, N.; Shinokubo, H.; Osuka, A., Post-Modification of meso-meso-Linked Porphyrin Arrays by Iridium and Rhodium Catalyses for Tuning of Energy Gap. Chem-Asian J 2009, 4 (7), 1126-1133.

160. Zenkevich, E.; von Borczyskowski, C., Primary Photoevents in Self-Assembled Complexes: Multiporphyrin Arrays and "Semiconductor CdSe/ZnS Nanocrystal-Porphyrin" Composites. Multiporphyrin Arrays: Fundamentals and Applications 2012, 217-288.

161. Mihara, N.; Yamada, Y.; Tanaka, K., Programmable Arrangement of Heterometal Ions in a Supramolecular Array of Porphyrin and Phthalocyanine. $B$ Chem Soc Jpn 2017, 90 (4), 427-435.

162. Yang, X. U.; Zhang, D.; Tang, R. R.; Chen, X. H., Progress in the Synthesis and Application of Porphyrin-Perylene Arrays. Chinese J Org Chem 2009, 29 (12), 1906-1923.

163. Minamiki, T.; Kubota, R.; Sasaki, Y.; Asano, K.; Minami, T., Protein Assays on Organic Electronics: Rational Device and Material Designs for Organic Transistor-Based Sensors. Chemistryopen 2020, 9 (5), 573-581.

164. Haft, M.; Knohl, S., PTS is a new Member of the OE-A (Organic and Printed Electronics Association) Network: New Opportunities \& Possibilities. Wochenbl Papierfabr 2020, 148 (1).

165. Chen, M. L.; Yin, B. S.; Song, J. X., Recent Development of Constructing Porphyrin Arrays via Suzuki-Miyaura Cross-Coupling Reaction. Prog Chem 2015, 27 (6), 641-654. 


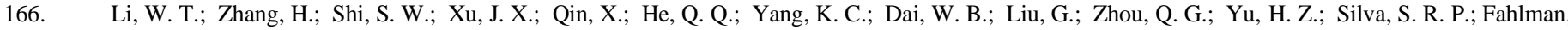
M., Recent progress in silver nanowire networks for flexible organic electronics. J Mater Chem C 2020, 8 (14), $4636-4674$.

167. Fang, Y. Y.; Jiang, X. Q.; Ou, Z. P.; Michelin, C.; Desbois, N.; Gros, C. P.; Kadish, K. M., Redox properties of nitrophenylporphyrins and electrosynthesis of nitrophenyl-linked Zn porphyrin dimers or arrays. J Porphyr Phthalocya 2014, 18 (8-9), 832-841.

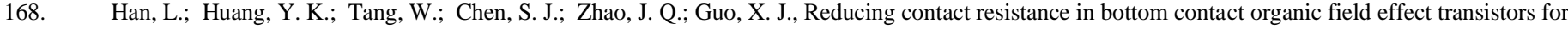
integrated electronics. J Phys D Appl Phys 2020, 53 (1).

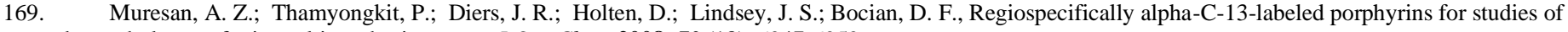
ground-state hole transfer in multiporphyrin arrays. J Org Chem 2008, 73 (18), 6947-6959.

170. Vijayaraghavan, S.; Auwarter, W.; Ecija, D.; Seufert, K.; Rusponi, S.; Houwaart, T.; Sautet, P.; Bocquet, M. L.; Thakur, P.; Stepanow, S.;

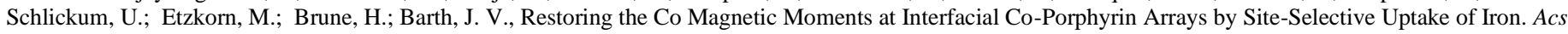
Nano 2015, 9 (4), 3605-3616.

171. Kwon, J. H.; Jeon, Y.; Choi, K. C., Robust Transparent and Conductive Gas Diffusion Multibarrier Based on Mg- and Al-Doped ZnO as Indium Tin Oxide-Free Electrodes for Organic Electronics. Acs Appl Mater Inter 2018, 10 (38), 32387-32396.

172. Spiess, H., Role of conformation of side groups in supramolecular organization of materials for organic electronics. Abstr Pap Am Chem $S$ 2019, 258.

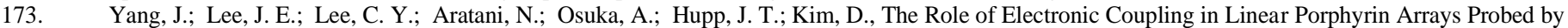

Single-Molecule Fluorescence Spectroscopy. Chem-Eur J 2011, 17 (33), 9219-9225.

174. Kim, D., The Role of Electronic Coupling in Various Porphyrin Arrays Probed by Raman and Single Molecule Fluorescence Spectroscopy. Aip Conf Proc 2010, 1267, 687-688.

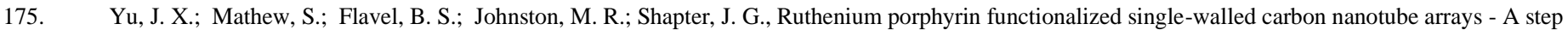
toward light harvesting antenna and multibit information storage. J Am Chem Soc 2008, 130 (27), 8788-8796.

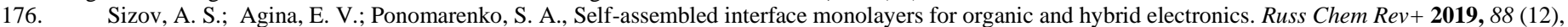
1220-1247.

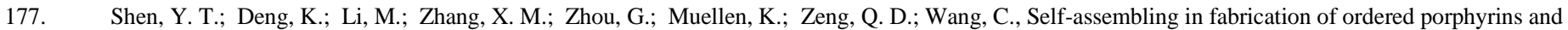
phthalocyanines hybrid nano-arrays on HOPG. Crystengcomm 2013, 15 (27), 5526-5531.

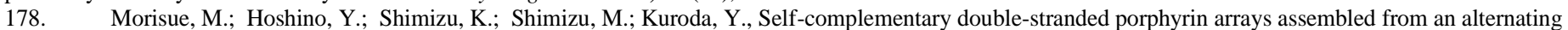
pyridyl-porphyrin sequence. Chem Sci 2015, 6 (11), 6199-6206.

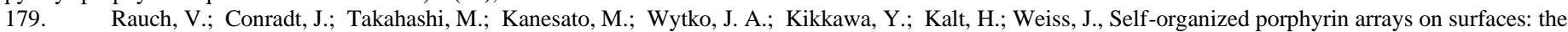
case of hydrophilic side chains and polar surfaces. J Porphyr Phthalocya 2014, 18 (1-2), 67-75.

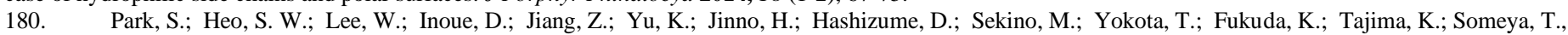
Self-powered ultra-flexible electronics via nano-grating-patterned organic photovoltaics. Nature 2018, 561 (7724), 516-+.

181. Kang, W. M.; Ma, X. M.; Hu, M.; Jia, Z. X.; Liu, H.; Cheng, B. W., Self-templating synthesis of a fluorescent porphyrin doped poly(methyl methacrylate) nano-array and its $\mathrm{HCl}$ gas sensing properties. Anal Methods-Uk 2016, 8 (35), 6489-6493.

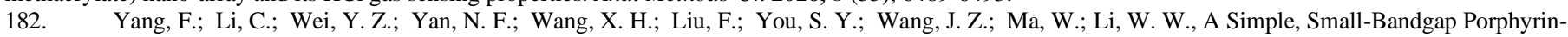
Based Conjugated Polymer for Application in Organic Electronics. Macromol Rapid Comm 2018, 39 (21).

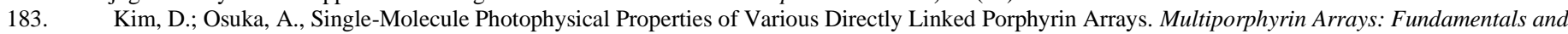
Applications 2012, 1-54.

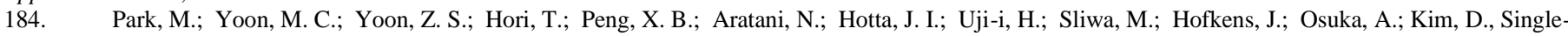
molecule spectroscopic investigation of energy migration processes in cyclic porphyrin arrays. J Am Chem Soc 2007, 129 (12), 3539-3544.

185. Shetti, V. S.; Pareek, Y.; Ravikanth, M., Sn(IV) porphyrin scaffold for multiporphyrin arrays. Coordin Chem Rev 2012, 256 (23-24), 2816-2842.

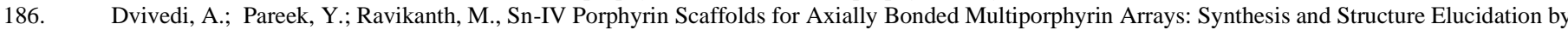

NMR Studies. Chem-Eur J 2014, 20 (15), 4481-4490.

187. Mardis, K. L.; Sutton, H. M.; Zuo, X. B.; Lindsey, J. S.; Tiede, D. M., Solution-State Conformational Ensemble of a Hexameric Porphyrin Array

Characterized Using Molecular Dynamics and X-ray Scattering. J Phys Chem A 2009, 113 (11), 2516-2523.

188. Salzillo, T.; Rivalta, A.; Castagnetti, N.; D'Agostino, S.; Masino, M.; Grepioni, F.; Venuti, E.; Brillante, A.; Girlando, A., Spectroscopic

identification of quinacridone polymorphs for organic electronics. Crystengcomm 2019, 21 (24), 3702-3708.

189. Xu, H.; Cao, K. D.; Ding, H. B.; Zhong, Q. F.; Gu, H. C.; Xie, Z. Y.; Zhao, Y. J.; Gu, Z. Z., Spherical Porphyrin Sensor Array Based on Encoded

Colloidal Crystal Beads for VOC Vapor Detection. Acs Appl Mater Inter 2012, 4 (12), 6751-6756.

190. Cammidge, A. N.; Nekelson, F.; Hughes, D. L.; Zhao, Z. X.; Cook, M. J., Stepwise syntheses of complex mu-oxo-linked heterochromophore arrays containing phthalocyanine, porphyrin and subphthalocyanine ligands. J Porphyr Phthalocya 2010, 14 (12), $1001-1011$.

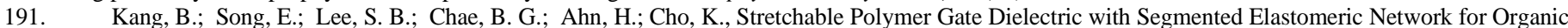
Soft Electronics. Chem Mater 2018, 30 (18), 6353-6360.

192. Ferdele, S.; Jose, B.; Foster, R.; Keyes, T. E.; Rice, J. H., Strong coupling in porphyrin J-aggregate excitons and plasmons in nano-void arrays. Opt Mater 2017, 72, 680-684.

193. Yoon, M. C.; Cho, S.; Kim, P.; Hori, T.; Aratani, N.; Osuka, A.; Kim, D., Structural Dependence on Excitation Energy Migration Processes in Artificial Light Harvesting Cyclic Zinc(II) Porphyrin Arrays. J Phys Chem B 2009, 113 (45), 15074-15082.

194. Lee, S. H.; Yang, J.; Kim, D., Structure-Dependent Electronic Interactions in Ethyne-Bridged Porphyrin Arrays Investigated by Single-Molecule Fluorescence Spectroscopy. J Phys Chem Lett 2016, 7 (18), 3676-3682.

195. Park, S. K.; Sun, H.; Chung, H.; Patel, B. B.; Zhang, F. J.; Davies, D. W.; Woods, T. J.; Zhao, K. J.; Diao, Y., Super- and Ferroelastic Organic Semiconductors for Ultraflexible Single-Crystal Electronics. Angew Chem Int Edit 2020.

196. Satake, A.; Shoji, O.; Kobuke, Y., Supramolecular array of imizazolylethynyl-zinc-porphyrin. J Organomet Chem 2007, 692 (1-3), 635-644.

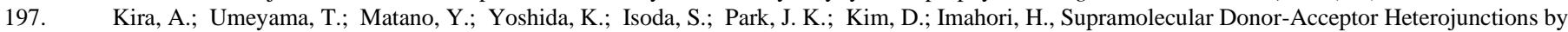

Vectorial Stepwise Assembly of Porphyrins and Coordination-Bonded Fullerene Arrays for Photocurrent Generation. J Am Chem Soc 2009, 131 (9), 3198-+.

198. Wang, H. W.; Chen, C. H.; Lim, T. S.; Huang, S. L.; Luh, T. Y., Supramolecular Porphyrin-DABCO Array in Single- and Double-Stranded Polynorbornenes. Chem-Asian J 2011, 6 (2), 524-533.

199. Witkowski, N., Surface and Interface Characterization in Organic Electronics. Wor Sci Ser Nano 2019, 17, $105-132$.

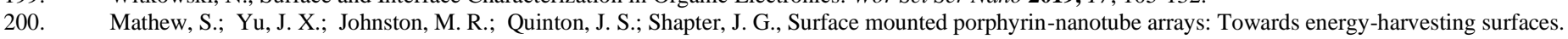
2008 International Conference on Nanoscience and Nanotechnology 2008, 206-209.

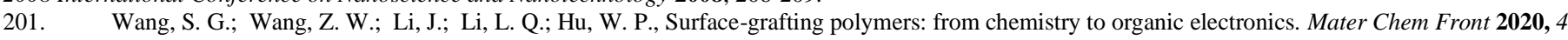
(3), 692-714

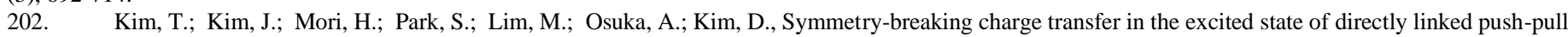
porphyrin arrays. Phys Chem Chem Phys 2017, 19 (21), 13970-13977.

203. Kanekar, D. N. N.; Chacko, S.; Kamble, R. M. M., Synthesis and investigation of the photophysical, electrochemical and theoretical properties of phenazine-amine based cyan blue-red fluorescent materials for organic electronics. New J Chem 2020, 44 (8), $3278-3293$. 
204. Finnigan, E. M.; Rein, R.; Solladie, N.; Dahms, K.; Gotz, D. C. G.; Bringmann, G.; Senge, M. O., Synthesis and ligand binding properties of triptycene-linked porphyrin arrays. Tetrahedron 2011, 67 (6), 1126-1134.

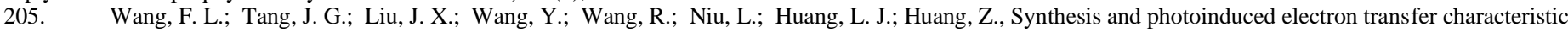
of a bis (zinc porphyrin)-perylene bisimide array. J Phys Org Chem 2011, 24 (11), 1101-1109.

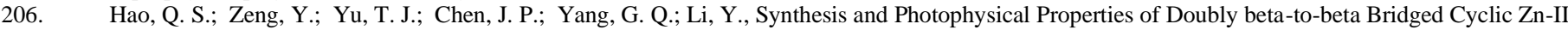
Porphyrin Arrays. Chem-Asian J 2013, 8 (5), 1015-1022.

207. Tan, K. X.; Lintang, H. O.; Maniam, S.; Langford, S. J.; Bakar, M. B., Synthesis and photophysical studies of fluorenone-armed porphyrin arrays. Tetrahedron 2016, 72 (35), 5402-5413.

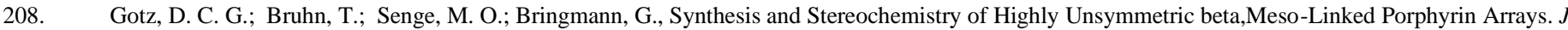
Org Chem 2009, 74 (21), 8005-8020.

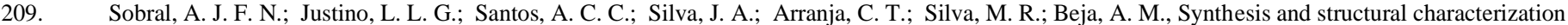
of a new self-assembled disulfide linked meso-tetrakis-porphyrin macromolecular array. J Porphyr Phthalocya 2008, 12 (7), $845-848$.

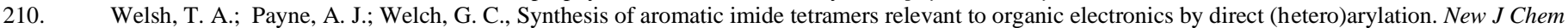
2019, 43 (24), 9333-9337.

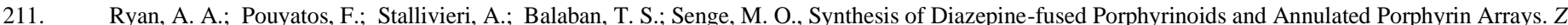
Naturforsch B 2014, 69 (8), 889-898.

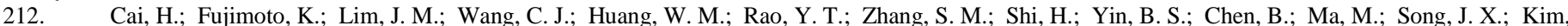

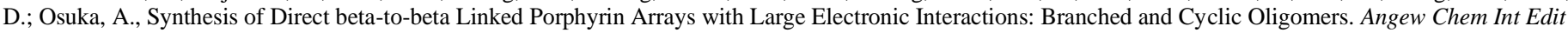
2014, 53 (41), 11088-11091.

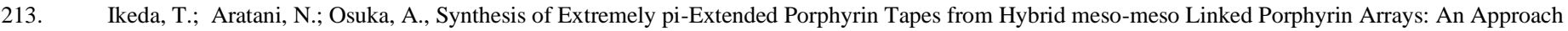
Towards the Conjugation Length. Chem-Asian J 2009, 4 (8), 1248-1256.

214. Golf, H. R. A.; Oltmanns, A. M.; Trieu, D. H.; Reissig, H. U.; Wiehe, A., Synthesis of Functionalized BODIPYs, BODIPY-Corrole, and BODIPYPorphyrin Arrays with 1,2,3-Triazole Linkers Using the 4-Azido(tetrafluorophenyl)-BODIPY Building Block. Eur J Org Chem 2015, (19), $4224-4237$.

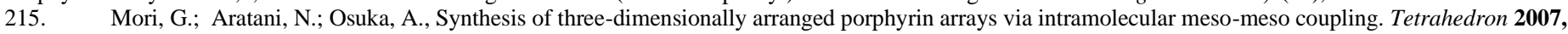
$63(33), 7916-7925$.

216. Langford, S. J.; Woodward, C. P., Synthesis, characterisation and X-ray structure of a novel porphyrin array employing Zn-O and O-H...O bonding motifs. Polyhedron 2007, 26 (2), 338-343.

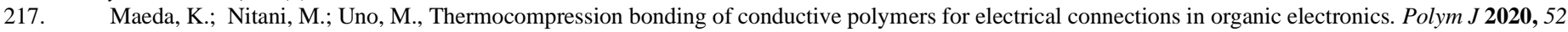
(4), 405-412.

218. Osuka, A., Towards meso-meso-Linked Porphyrin Arrays and meso-Aryl Expanded Porphyrins. Chem Rec 2015, 15 (1), $143-159$.

219. Zani, L.; Dessi, A.; Franchi, D.; Calamante, M.; Reginato, G.; Mordini, A., Transition metal-catalyzed cross-coupling methodologies for the engineering of small molecules with applications in organic electronics and photovoltaics. Coordin Chem Rev 2019, $392,177-236$.

220. Yamada, Y.; Mihara, N.; Shibano, S.; Sugimoto, K.; Tanaka, K., Triply Stacked Heterogeneous Array of Porphyrins and Phthalocyanine through Stepwise Formation of a Fourfold Rotaxane and an Ionic Complex. J Am Chem Soc 2013, 135 (31), 11505-11508.

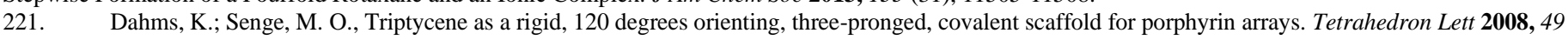
(37), 5397-5399.

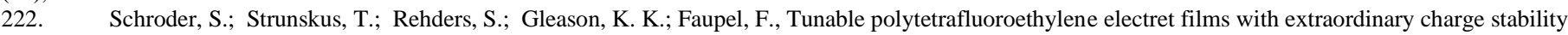
synthesized by initiated chemical vapor deposition for organic electronics applications. Sci Rep-Uk $2019,9$.

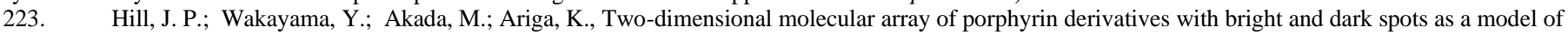
two-digit molecular-dot memory. Synthetic Met 2009, 159 (9-10), 765-768.

224. Cebrian, C., Ullazine-based materials: towards novel opportunities in organic electronics. J Mater Chem C 2018, 6 (44), $11943-11950$.

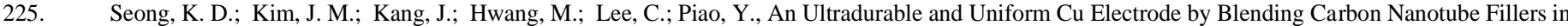
Copper-Based Metal-Organic Decomposition Ink for Flexible Printed Electronics. Adv Mater Interfaces 2018, 5 (16).

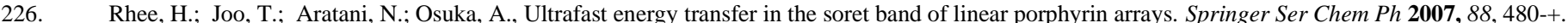

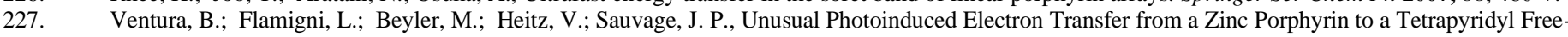
Base Porphyrin in a Noncovalent Multiporphyrin Array. Chem-Eur J 2010, 16 (29), 8748-8756.

228. Leonardi, M. J.; Palomaki, P. K. B.; Dinolfo, P. H., Using copper(I)-catalyzed azide-alkyne cycloaddition in the creation of triazole linked multiporphyrin arrays. Abstr Pap Am Chem S 2010, 240.

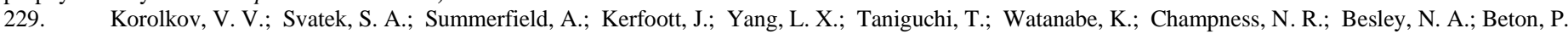
H., van der Waals-Induced Chromatic Shifts in Hydrogen-Bonded Two-Dimensional Porphyrin Arrays on Boron Nitride. Acs Nano 2015, 9 (10), 10347-10355.

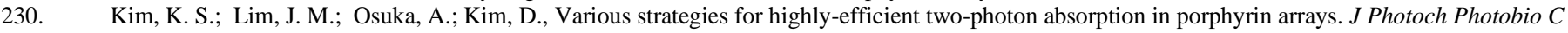
2008, 9 (1), 13-28

231. Seo, D. G.; Lee, Y.; Go, G. T.; Pei, M.; Jung, S.; Jeong, Y. H.; Lee, W.; Park, H. L.; Kim, S. W.; Yang, H.; Yang, C.; Lee, T. W., Versatile neuromorphic electronics by modulating synaptic decay of single organic synaptic transistor: From artificial neural networks to neuro-prosthetics. Nano Energy 2019, 65 .

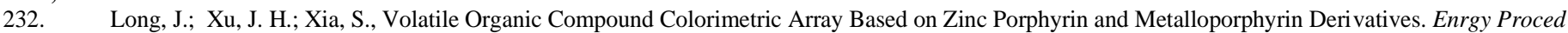
2011, 12 .

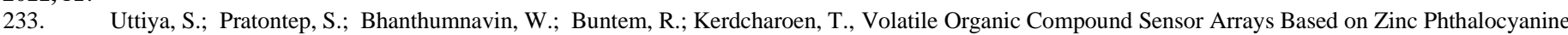
and Zinc Porphyrin Thin Films. 2008 2nd Ieee International Nanoelectronics Conference, Vols 1-3 2008, 618-+. 